\title{
Epidermal Growth Factor Receptor (EGFR) Phosphorylation, Signaling and Trafficking in Prostate Cancer
}

\author{
Yao Huang and Yongchang Chang \\ St. Joseph's Hospital and Medical Center, Phoenix, Arizona
}

USA

\section{Introduction}

The molecular mechanisms of prostate cancer are still poorly understood, despite the threat that prostate cancer poses to the health of men worldwide. As prostate tumors are initially dependent on androgens for growth and survival, androgen deprivation therapy is the firstline treatment for prostate cancer patients. However, a hormonal-refractory (androgen independent) state often develops afterwards, and principal treatment options are palliative because of the tumor progression, which is characterized by uncontrolled growth and metastasis associated with androgen independence. To date, no effective therapy can abrogate prostate cancer progression to advanced, invasive forms. Recent evidence suggests that acquisition of androgen-independence may be due to upregulation of growth factor receptor signaling pathways, principally the epidermal growth factor receptor (EGFR)/ErbB/human epidermal receptor (HER) family (Craft et al., 1999), making it an attractive target for therapeutic intervention. EGFR/ErbB/HER signaling in cancer has been extensively studied for decades, and there have been a number of excellent reviews on the roles of ErbB receptors in the initiation and progression of a wide variety of cancers, including prostate cancer (Laskin \& Sandler, 2004; Ratan et al., 2003; Yarden \& Sliwkowski, 2001). Thus, this review chapter will focus more narrowly on EGFR phosphorylation, signaling, and trafficking, and their specific roles in prostate cancer development and progression (tumor growth and metastasis) given the growing literature in this area. Better understanding of the precise roles of divergent EGFR signaling pathways and their phenotypic consequences in prostate cancer (and normal prostate) will enable the development of more effective and selective therapies for this urologic disease.

\section{Overview of the EGF/EGFR signaling system}

\subsection{The EGFR/ErbB/HER family and ligands}

EGFR/ErbB1/HER1 is the prototype of the EGFR or ErbB family, which also includes other three receptor tyrosine kinases, ErbB2/HER2/Neu, ErbB3/HER3, and ErbB4/HER4 (Figure 1). All four members have in common an extracellular ligand-binding domain, a single hydrophobic transmembrane domain, and a cytoplasmic region that contains a highly conserved tyrosine kinase domain and C-terminal tail (Wells, 1999). However, ErbB3 lacks intrinsic tyrosine kinase activity due to substitutions of critical amino acids within the kinase 
domain (Guy et al., 1994). The extracellular domains are less conserved among the four, suggesting their ligand binding specificity (Yarden, 2001; Yarden \& Sliwkowski, 2001).

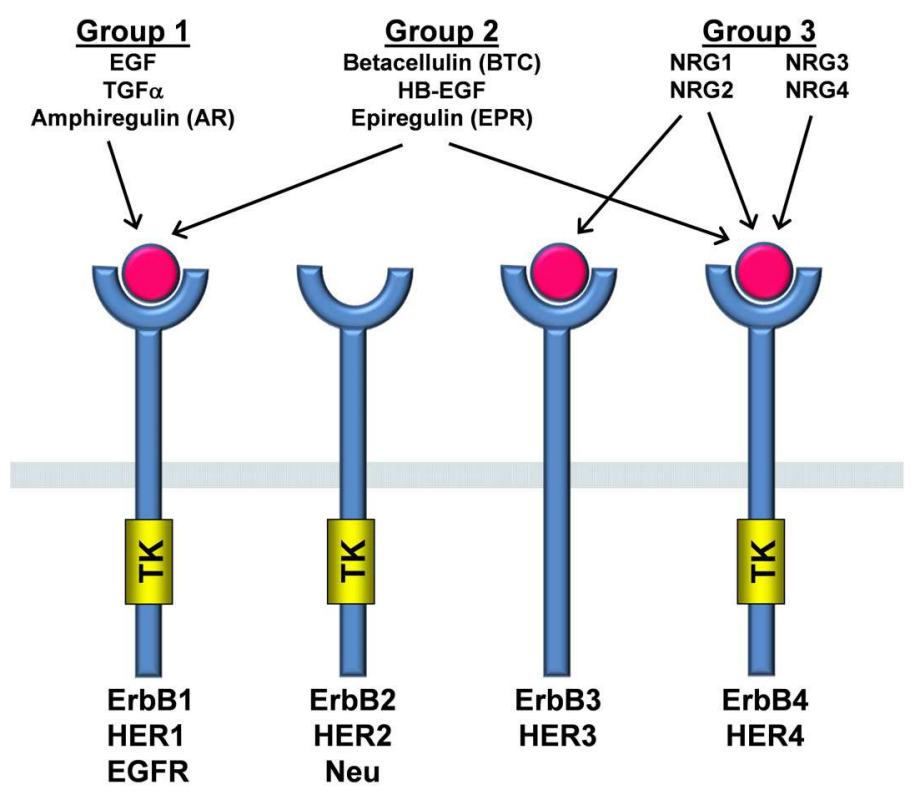

Fig. 1. The four EGFR/ErbB family members and their ligands. TK, tyrosine kinase domain. See the text for more details.

ErbB receptors are activated by a number of ligands that belong to the EGF family of peptide growth factors (Citri \& Yarden, 2006; Yarden, 2001). The EGF-related growth factors are characterized by the presence of an EGF-like domain consisting of three disulfide-bonded intramolecular groups conferring binding specificity, and additional structural motifs such as immunoglobulin-like domains, heparin-binding sites and glycosylation sites. They are produced as transmembrane precursors that are biologically active and able to interact with receptors expressed on adjacent cells, and the ectodomains are processed by proteolysis, resulting in the shedding of soluble growth factors (Massagué \& Pandiella, 1993). Based on their affinity for one or more ErbBs, the EGFrelated growth factors are generally classified into three groups (Yarden \& Sliwkowski, 2001) (Figure 1). The first group includes EGF, transforming growth factor- $\alpha$ (TGF- $\alpha$ ) and amphiregulin (AR), which bind specifically to EGFR. The second group includes betacellulin (BTC), heparin-binding EGF (HB-EGF), and epiregulin (EPR), which exhibit dual specificity for both EGFR and ErbB4 (Yarden, 2001). The third group includes nuregulins (NRG, also called Neu differentiation factors (NDF) or heregulins (HRG)) that can be divided into two subgroups based on their binding specificity to both ErbB3 and ErbB4 (NRG-1 and NRG-2) or only ErbB4 (NRG-3 and NRG-4) (Harari et al., 1999; Zhang et al., 1997). Despite intensive efforts, no direct ligand for ErbB2 has yet been discovered. Increasing evidence suggests that ErbB2 primarily functions as a coreceptor for other ErbB family members (Graus-Porta et al., 1997; Tzahar et al., 1996). 


\subsection{Major EGF/EGFR signaling pathways}

The repertoire of ErbB ligands and the combinatorial properties of ligand-induced receptor dimers give rise to the signaling diversity of the ErbB family. Ligand binding drives receptor homo- or hetero-dimerization, leading to activation of the intrinsic tyrosine kinase and subsequent auto- or trans-phosphorylation of specific tyrosine residues in the cytoplasmic tail (Citri \& Yarden, 2006; Olayioye et al., 2000; Yarden \& Sliwkowski, 2001), which provide the docking sites for proteins containing Src homology 2 (SH2) or phosphotyrosine binding (PTB) domains (Shoelson, 1997; Sudol, 1998). These proteins generally include the adaptor proteins such as Src homology domain-containing adaptor protein C (Shc), Crk, growth factor receptorbound protein 2 (Grb2), Grb7, Grb2-associated binding protein 1 (Gab1), phospholipase $C_{\gamma}$ (PLCY), Cbl, Esp15; the kinases such as Src, Chk and phosphatidylinositol-3-kinase (PI3K; via the p85 regulatory subunit); and the protein tyrosine phosphatases such as PTP1B, SHP1 and SHP2 (Olayioye et al., 2000; Sebastian et al., 2006), suggesting diversity and complexity of ErbB signaling networks. Among them, the signaling elicited by EGF-induced EGFR homodimers is perhaps the best studied and has served as the prototype for other cases.

Adaptor proteins, kinases, and phosphatases recruited by the activated EGFR transmit signals from the receptor through different downstream signaling pathways to the nucleus to regulate various biological functions such as cell proliferation, differentiation, antiapoptosis (survival), adhesion, migration, and angiogenesis (Baselga \& Hammond, 2002; Laskin \& Sandler, 2004; Morandell et al., 2008; Yarden \& Sliwkowski, 2001). So far with the numbers still growing, over one hundred EGFR interacting proteins have been described in the literature, of which many were discovered by proteomics approaches (Morandell et al., 2008). Approximately twenty phosphotyrosine residues located within the EGFR cytoplasmic tail have been identified as specific docking sites for above-mentioned EGFR interacting partners to engage various signaling cascades (Figure 2). The major EGF/EGFR signaling pathways include Ras/Raf/MAPK kinase (MEK)/extracellular-related kinase (ERK) and PI3K/Akt (Hirsch et al., 2003; Singh \& Harris, 2005), although other pathways such as $\mathrm{PLC} \gamma /$ protein kinase $\mathrm{C}$ (PKC), signal transducer and activator of transcription (STAT) (Andl et al., 2004; Kloth et al., 2002), c-Jun terminal kinase (JNK) and p38 MAPKs (Johnson et al., 2005), and $\mathrm{Ca}^{2+}$-calmodulin-dependent protein kinase (CaMK) (Sengupta et al., 2009) have been reported. It is also known that upon EGF binding, EGFR undergoes a process of internalization, ubiquitination (via $\mathrm{Cbl}$ ), destruction (namely EGFR endocytosis and trafficking), resulting in temporary EGFR downregulation (Citri \& Yarden, 2006; Sebastian et al., 2006; Wiley, 2003). This will be discussed in Section 3.

\subsection{EGFR signaling in prostate cancer development}

Both clinical and experimental data have established the importance of ErbBs, especially EGFR and ErbB2, in carcinogenesis and progression of various types of solid tumors including prostate cancer (Harari, 2004; Laskin \& Sandler, 2004; Sebastian et al., 2006; Yarden \& Sliwkowski, 2001). Increased expression and signaling of EGFR and/or ErbB2 are associated with a more aggressive clinical behavior of tumors, and correlate with a poor prognosis (Alroy \& Yarden, 1997; Hatake et al., 2007; Lichtner, 2003; Nicholson et al., 2001). There are estimated $40-80 \%$ of prostate tumors with expressed EGFR (Kim et al., 1999; Sebastian et al., 2006). Studies mainly from breast cancer, lung cancer, and glioma have suggested many potential mechanisms related to aberrant EGFR signaling (quantitatively and/or qualitatively). These include elevated expression of ligands and/or receptors, enhanced autocrine signaling loop, constitutive activation of EGFR mutants, impaired endocytosis and trafficking of the ligand- 
receptor complex, hetero-dimerization with other ErbBs (Ciardiello \& Tortora, 2003; Grandal \& Madshus, 2008; Huang et al., 2009; Olayioye et al., 2000; Roepstorff et al., 2008; Sebastian et al., 2006; Sharma et al., 2007), as well as crosstalk with other receptor signaling systems such as type 1 insulin-like growth factor receptor (IGF-1R), G-protein-coupled receptors (GPCRs), and cytokine receptors (Adams et al., 2004; Gee et al., 2005; Prenzel et al., 2000).

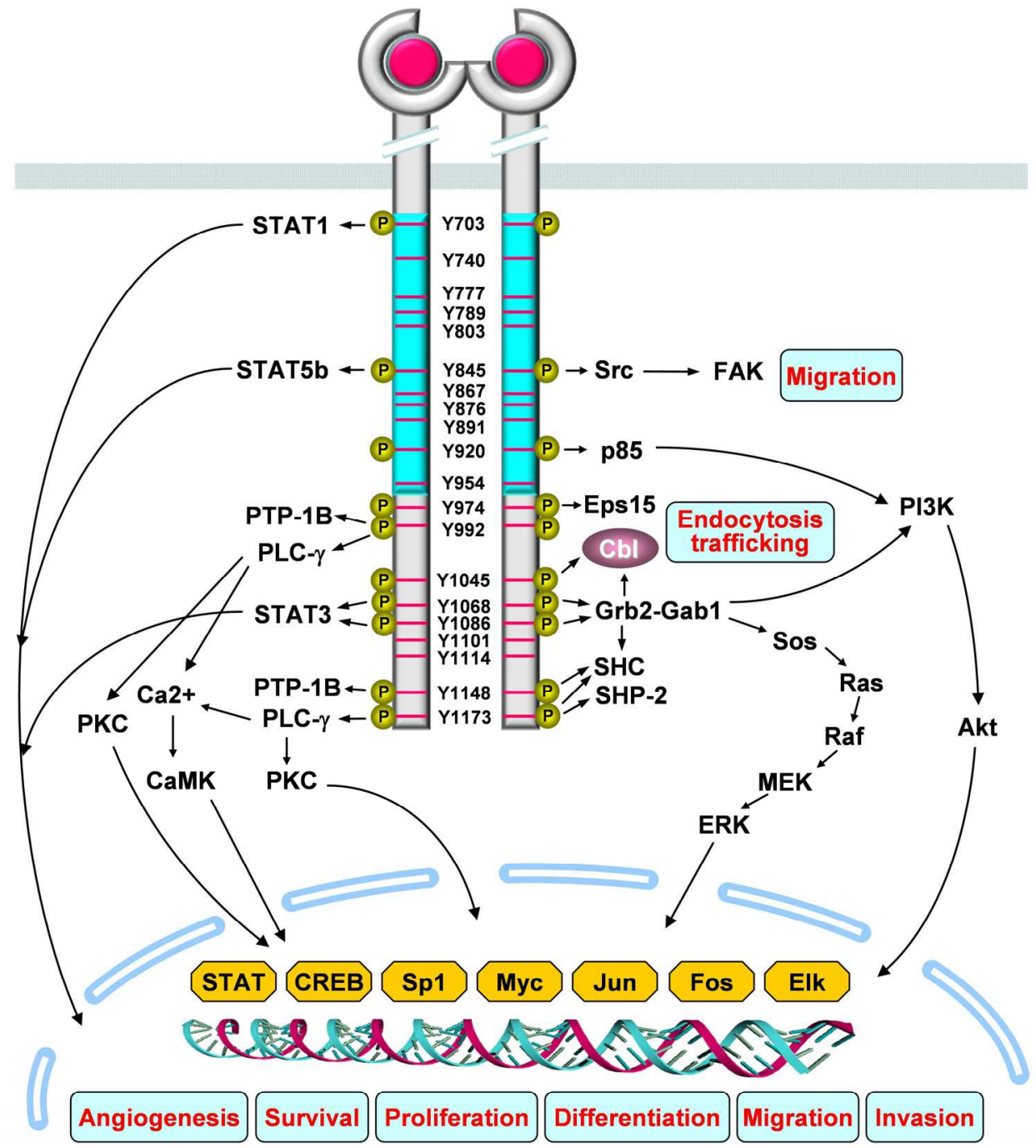

Fig. 2. EGF/EGFR-mediated signaling pathways and cellular effects. Major tyrosine phosphorylation sites in the EGFR cytoplasmic tail, possible adaptors and signaling proteins, and signaling cascades are indicated. See the text for more details.

Progression from normal prostate epithelium to an androgen-responsive tumor, and finally to hormone-refractory carcinoma is a multistep process, usually accompanied by the 
upregulation of growth factor receptors and/or their ligands, and downregulation of tumor suppressor gene products (Djakiew, 2000; Ware, 1999). EGFR ligands, such as EGF, HB-EGF, and TGF- $\alpha$, are expressed in the prostate and prostatic carcinomas (Elson et al., 1984; Freeman et al., 1998). In particular, the expression of TGF-a (signaling merely through EGFR) has been found to be greater in some higher grade and metastatic prostate cancers than in primary low grade tumors (Scher et al., 1995). It is now more widely believed that EGF is the predominant EGFR ligand in early, localized prostate cancer, and that TGF- $\alpha$ becomes more abundant than EGF at advanced, metastatic stages (Liu et al., 1993; Scher et al., 1995; Seth et al., 1999). This is the so-called EGFR ligand switch (DeHaan et al., 2009). Overexpression of EGFR and/or ErbB2 would have been expected in prostate carcinomas, as seen in breast cancer (Hatake et al., 2007; Lichtner, 2003; Nicholson et al., 2001). However, current data regarding ErbB receptor overexpression in prostate cancer appear to conflict with each other, possibly due to technical reasons and lack of standardized measurement and evaluation methods (Marks et al., 2008; Neto et al., 2010; Salomon et al., 1995; Schlomm et al., 2007; Sherwood \& Lee, 1995). Nevertheless, several lines of evidence strongly support the important role of EGFR signaling in prostate cancer development. For example, autocrine activation of EGFR signaling by EGF and TGF-a most likely drives the autonomous growth of human prostate cancer (Hofer et al., 1991; Scher et al., 1995). Expression of mutant EGFRs also contributes to prostate carcinogenesis and malignant progression (Cai et al., 2008; Douglas et al., 2006; He \& Young, 2009; Olapade-Olaopa et al., 2000). Taken together, studies over the years have suggested that both EGFR and ErbB2 signaling play important roles in prostate cancer development and, more specifically, in the progression from an androgen-dependent to a hormone-refractory state.

\section{EGF/EGFR endocytosis and trafficking}

As just described, aberrant EGFR signaling is frequently associated with carcinogenesis and cancer progression. This can be the result of several unbalanced mechanisms controlling the quantitative and qualitative output of EGFR, such as elevated expression of receptors and ligands, activating receptor mutations, and impaired endocytic receptor downregulation. Proper endocytic uptake and endosomal sorting of signaling receptors have been considered as a crucial step for precisely controlling cellular processes such as growth, differentiation, and survival. Our current understanding of ligand-induced receptor endocytic downregulation is largely from the knowledge of EGFR trafficking routes following EGF binding, which has historically been and remains to be the most popular experimental system for studies in this field. In contrast, very little is known about endocytosis of ErbB2-4, as well as about EGFR endocytosis following binding of ligands other than EGF.

It is generally believed that EGFR is present at the plasma membrane as a monomer prior to activation. Ligand (EGF) binding triggers EGFR dimerization and activation of its intrinsic kinase, leading to signaling and relocation to invaginating clathrin-coated pits (CCPs) on the plasma membrane. The CCPs give rise to clathrin-coated endocytic vesicles. The vesicles are then released from the membrane and fuse with early endosomes. Thus, EGFR is delivered to this compartment by these sequential processes. From here the receptor is sorted for further transport, either back to the cell surface by recycling, or to the multivesicular bodies (MVBs), a pathway for eventual delivery of EGFR to late endosomes and lysosomes for degradation, which results in temporary EGFR downregulation (Figure 3). Under most physiological 
conditions, clathrin-dependent pathways are considered to be the main routes of EGFR internalization and downregulation. However, clathrin-independent pathways have also been reported and suggested as alternative mechanisms for EGFR endocytosis (Orth et al., 2006; Sigismund et al., 2005; Yamazaki et al., 2002), which will not be discussed here.

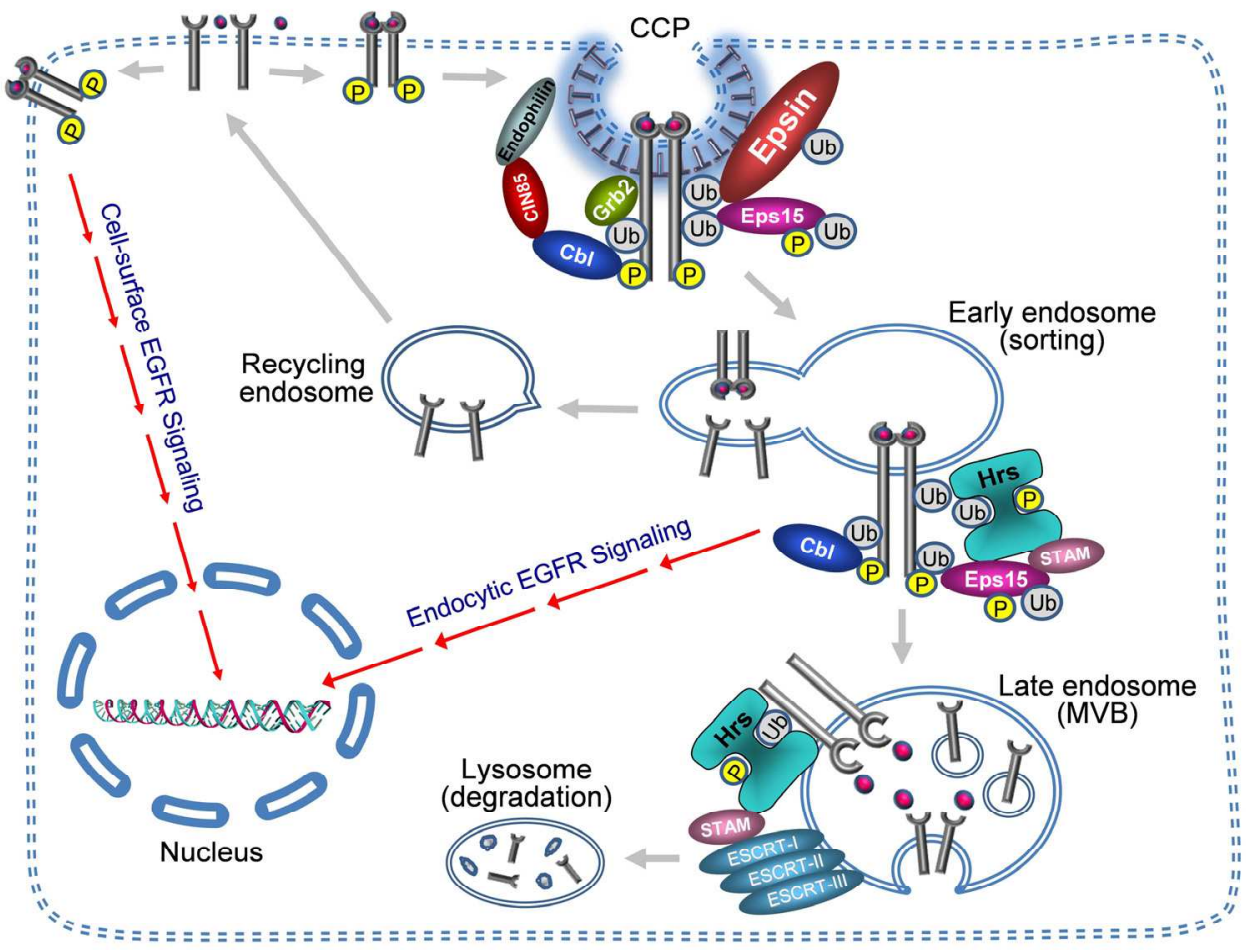

Fig. 3. EGFR endocytosis, trafficking, and turnover. EGF engagement results in EGFR activation and signaling from the cell surface. Upon EGF binding, EGFRs are internalized into clathrin-coated pits (CCP). Activated EGFR recruits the E3 ubiquitin ( $\mathrm{Ub}$ ) ligase $\mathrm{Cbl}$, which ubiquitinates EGFR. EGFRs are delivered to early endosomes. From here, the receptors are sorted for either recycling back to the plasma membrane or transferring via multivesicular bodies (MVB) to late endosomes/lysosomes for degradation. The activated EGFR can continuously signal from endosomes or during its postendocytic trafficking. See the text for more details.

\subsection{Ubiquitination and internalization of EGFR}

Although the major steps of EGF/EGFR endocytosis and trafficking pathways are well established (Grandal \& Madshus, 2008; Wiley, 2003), the molecular machinery controlling these processes remains poorly understood. It is believed that ubiquitination plays a key role in "tagging" or sorting EGFR for endocytosis and degradation (Hicke, 1999). Cbl is a ring-finger domain E3 ubiquitin ligase that is mainly responsible for EGFR ubiquitination (Levkowitz et al., 1998; Waterman et al., 1999). Upon EGF binding to EGFR, Cbl proteins are tyrosine phosphorylated by Src kinases (Feshchenko et al., 1998) and recruited rapidly to the 
activated EGFR to mediate the receptor ubiquitination (Sebastian et al., 2006). Cbl can bind to EGFR either directly at phosphorylated tyrosine residue 1045 (Y1045) or indirectly via adaptor protein Grb2, which binds to phosphorylated EGFR at Y1068 and Y1086 (Levkowitz et al., 1999; Waterman et al., 2002). However, these two Cbl-EGFR interaction mechanisms have different effects on EGFR endocytosis. Direct binding via Y1045 may not be necessary for EGFR endocytosis, as the Y1045F mutation of EGFR results in impaired ubiquitination but does not affect receptor internalization (Grøvdal et al., 2004; Jiang et al., 2003). In contrast, Grb2-mediated binding is essential and sufficient for EGFR internalization. This is supported by the fact that Grb2 knockdown inhibits EGFR endocytosis and a chimeric protein consisting of the Y1068/Y1086-binding domain of Grb2 fused to Cbl can rescue the EGFR internalization in Grb2-depleted cells (Huang \& Sorkin, 2005).

In addition to acting as an E3 ubiquitin ligase, Cbl may have other functions in EGFR endocytic signaling. Phosphorylated $\mathrm{Cbl}$ can bind to the $85 \mathrm{kDa} \mathrm{Cbl}$ interacting protein (CIN85) that is constitutively associated with endophilin (Soubeyran et al., 2002), a known regulator of clathrin-mediated endocytosis (CME) (Reutens \& Begley, 2002). The recruitment of CIN85 and endophilin to EGFR by Cbl plays an important role in EGF-induced EGFR internalization and downregulation (Soubeyran et al., 2002). Furthermore, Eps15 and epsin, the two adaptor proteins with ubiquitin binding capacity and known to localize to CCPs, are required for EGFR internalization and possibly form a complex with ubiquitinated EGFR (Polo et al., 2002; Roepstorff et al., 2008; Salcini et al., 1999). Interestingly, it has been reported that Esp15 localizes at the rim of CCPs (Stang et al., 2004; Tebar et al., 1996), while epsin localizes along the entire CCP curvature (Stang et al., 2004). These findings suggest that EGFR (ubiquitinated by $\mathrm{Cbl}$ ) is captured by Eps15 and subsequently handed off to epsin deeper in the coated pits, which could be a more efficient way of EGFR progression into CCPs (Grandal \& Madshus, 2008).

As shown above, many lines of evidence indicate that functional $\mathrm{Cbl}$ is a prerequisite for EGFR internalization and that $\mathrm{Cbl}$ ubiquitinates EGFR. However, the role of EGFR ubiquitination as an internalization signal remains controversial. One study reported that an ubiquitination-deficient mutant of EGFR with full kinase activity can still undergo normal internalization (Huang et al., 2007). Several studies also showed that siRNA depletion of epsin and/or Eps15 did not specifically affect the clathrin-mediated EGFR internalization (Chen \& Zhuang, 2008; F. Huang et al., 2004; Sigismund et al., 2005; Vanden Broeck \& De Wolf, 2006). A very recent study has demonstrated that CME of activated EGFR is regulated by four mechanisms, which function in a redundant and cooperative fashion (Goh et al., 2010). All these imply that the EGFR endocytosis is a rather complicated process whose molecular mechanisms deserve further investigation.

\subsection{Ubiquitination and endosomal sorting of EGFR}

Upon EGF binding, activated EGFR undergoes CME at a much enhanced rate compared to the constitutive (ligand-independent) rate (Wiley, 2003). Immediately after internalization by CME, EGFR is delivered to early endosomes for sorting to either recycled back to the plasma membrane or transferred via MVBs to late endosomes/lysosomes for degradation (Figure 3). If not recycled back to the cell surface (as in the absence of EGF stimulation), EGFRs are sorted for lysosomal degradation. The latter is initiated by forming a complex with Esp15, signal transduction adaptor molecule (STAM), and hepatocyte growth factorregulated tyrosine kinase substrate (Hrs) (Bache et al., 2003). Hrs directs the receptors to 
tumor susceptibility gene-101 (TSG101). The endosomal sorting complex required for transport (ESCRT) complexes (ESCRT-I to III) are sequentially recruited. These processes eventually lead to the translocation of EGFRs into the intralumenal vesicles (ILVs) of MVBs and MVS fusion with lysosomes for receptor degradation and signal termination (Bache et al., 2006; Katzmann et al., 2002; Q. Lu et al., 2003; Williams \& Urbé, 2007).

In contrast to its controversial role in EGFR internalization (see above), it is clear that Cblmediated EGFR ubiquitination plays a pivotal role at the early endosome to the late endosome/lysosome sorting step of EGFR downregulation (Duan et al., 2003). EGFR mutants with reduced ubiquitination display impaired downregulation or degradation (Grøvdal et al., 2004; Huang et al., 2007; F. Huang et al., 2006; Jiang \& Sorkin, 2003; Levkowitz et al., 1999), and the Y1045F mutant can not translocate to ILVs (Grøvdal et al., 2004). Thus, it can be concluded from these studies that Cbl-associated ubiquitination is the signal for EGFR downregulation.

\subsection{EGFR signaling from the endosome}

EGF binding leads to and accelerates internalization and lysosomal degradation of EGFR. The most obvious function of receptor endocytosis is to remove activated EGF/EGFR complexes from the cell surface to achieve consumption of ligand and activated receptors and to prevent excessive signaling. Thus, the canonical view holds that endocytosis is a mechanism to attenuate receptor signaling via receptor downregulation. On the other hand, it has been known for many years that activated EGFR following EGF stimulation remains at the cell surface only briefly (5-10 min), and the majority of activated receptors are located in endosomes for a much longer time $(1 \mathrm{~h})$ (Lai et al., 1989; Sebastian et al., 2006; Wiley, 2003). Accumulating evidence indicates that the activated EGFR can continuously signal from endosomes or during its postendocytic trafficking (Baass et al., 1995; Carpenter, 2000; Pennock \& Wang, 2003; Wang et al., 2002a).

Studies of EGFR signaling in the context of endocytosis have uncovered that endosomeassociated EGFR is linked to many, if not all, of its downstream signaling cascades, suggesting the complex and multifaceted effects of EGFR endocytosis on its signaling. Early work done in rat liver parenchyma (in vivo) has demonstrated that, shortly after EGF administration (1 min), internalized activated EGFR recruits a protein complex of Shc, Grb2, and the son of sevenless (Sos) to endosomes, leading to endosomally localized activation of the Ras/Raf/MEK/ERK pathway (Di Guglielmo et al., 1994). In mice, the MEK1 binding partner (MP1), adaptor protein p14, and MEK1 form a complex in endosomes. Such endosomal p14-MP1-MEK1 signaling plays an important role in cell proliferation during tissue homeostasis (Teis et al., 2006; Teis et al., 2002). Further, appropriate trafficking of activated EGFRs through endosomes ensures spatial and temporal fidelity of MAPK signaling (Taub et al., 2007). An elegant work in which EGFR is specifically activated when it is endocytosed into endosomes, has established that internalized EGFR can exert signals from endosomes to control cell survival (Wang et al., 2002a; Wang et al., 2002b), possibly by stimulating the PI3K/Akt pathway (Haugh \& Meyer, 2002; Sorkin \& von Zastrow, 2009). Finally, it has been reported that EGFR endocytosis is essential for STAT3 nuclear translocation and STAT3-dependent gene regulation, suggesting that endocytosis is the transport machinery for STAT3 translocation through the cytoplasm to the nucleus (Bild et al., 2002). Collectively, ligand-activated EGFR has been demonstrated to continue to signal along the endocytic pathway, which contributes to the spatio-temporal regulation of signaling, i.e. determining the specificity of signals and controlling the strength and duration of signaling. 


\section{ERK-dependent EGFR phosphorylation and its impact on EGFR trafficking}

\subsection{Ras/Raf/MEK/ERK signaling pathway}

The Ras/Raf/MEK/ERK cascade is one of the major and best studied EGFR downstream pathways, which links extracellular signals to the machinery that can regulate diverse and fundamentally important cellular processes such as cell proliferation, differentiation, migration, apoptosis, angiogenesis, and chromatin remodeling (Dunn et al., 2005; Yoon \& Seger, 2006). Upon ligand binding, receptor dimerization, and EGFR intrinsic kinase activation and auto-phosphorylation, activation of the ERK pathway is triggered by Grb2 binding directly to EGFR at Y1068 and Y1086 and indirectly through Shc binding at Y1148 and Y1173 (Batzer et al., 1994; Lowenstein et al., 1992) (Figure 2). Grb2 recruits Sos guanine nucleotide exchange factor to the receptor complex and Sos mediates the route of activation of Ras proteins (H-Ras, K-Ras, and N-Ras) at the plasma membrane (Downward, 1996; Quilliam et al., 1995). Ras activation induces the activation of Raf family kinases including A-Raf, B-Raf, and C-Raf (Raf-1) (Marais et al., 1997; Marais \& Marshall, 1996). The active Raf then activates MEK1 and MEK2 by phosphorylating serines 218 and 222 in the activation loop, which further phosphorylate and activate ERK1 and ERK2 (Dhillon et al., 2007; McKay \& Morrison, 2007). These active ERKs phosphorylate numerous cytoplasmic and nuclear targets including kinases, phosphatases, transcription factors, and cytoskeletal proteins (Yoon \& Seger, 2006). We have recently uncovered ERK activation-dependent phosphorylation of EGFR in several cell systems including human prostate cancer cells, which can have profound feedback to EGFR signaling and trafficking and EGFR-driven cell migration. These previously understudied aspects are further discussed below.

\subsection{ERK activity-dependent phosphorylation of EGFR at threonine-669}

As illustrated in Figure 2, EGF binding to EGFR causes activation of the receptor tyrosine kinase and phosphorylation at multiple tyrosine residues in the cytoplasmic tail. Besides the tyrosine phosphorylation events, EGFR can be phosphorylated at several serine and threonine residues (Bao et al., 2000; Countaway et al., 1990; Theroux et al., 1992a), which may influence the EGFR kinase activity (Countaway et al., 1992; Theroux et al., 1992b). We have recently uncovered a previously unappreciated type of EGFR phosphorylation induced by EGF stimulation in several cell types. By employing a state-specific monoclonal antibody (mAb), PTP101, which specifically recognizes phosphorylation of the consensus site(s) (serine or threonine residues) in the substrates for proline-directed protein kinases such as ERKs (Pearson \& Kemp, 1991), we initially observed that upon EGF stimulation, both EGFR and ErbB2 undergo PTP101-reactive phosphorylation in addition to tyrosine phosphorylation in murine 3T3-F442A preadipocytes (Huang et al., 2003). Such PTP101reactive phosphorylation seems to correlate well with EGF-induced ERK activation, as the phosphorylation can be specifically inhibited by pretreatment of the cells with two separate MEK1 inhibitors, PD98059 and UO126 (Huang et al., 2003). Furthermore, we found that peptide hormones, such as growth hormone $(\mathrm{GH})$ and prolactin, can activate ERKs and cause PTP101-reactive phosphorylation of both EGFR and ErbB2 in 3T3-F442A (Huang et al., 2003) and human T47D breast cancer cells (Y. Huang et al., 2006), respectively. Previous studies suggested that serine/threonine phosphorylation of EGFR and ErbB2/Neu induced by the phorbol ester (PMA) and platelet-derived growth factor (PDGF) are attributable to the activation of PKC (Bao et al., 2000; Davis \& Czech, 1985; Davis \& Czech, 1987; Epstein et al., 1990; Hunter et al., 1984; Lund et al., 1990). Our data showed that neither GH-induced 
ERK activation nor EGFR and ErbB2 PTP101 reactivity are affected by the PKC inhibitor (GF109203X), though the MEK1 inhibitors (PD98059 and UO126) are indeed inhibitory (Huang et al., 2003). Similar results have been obtained for prolactin-induced ERK activation and PTP101-reactivity of EGFR in T47D cells (Y. Huang et al., 2006). Collectively, our data suggests that the mAb PTP101 detects ERK-dependent, rather than PKC-dependent, serine/threonine phosphorylation of EGFR and ErbB2, and that EGF/GH/prolactin-induced and PMA-induced phosphorylation may have distinct mechanisms (Huang et al., 2003; Y. Huang et al., 2006). Interestingly, we have recently demonstrated that such an EGF-induced serine/threonine phosphorylation of EGFR also occurs in human prostate cancer cells, which requires activation of ERK pathway but not Akt pathway (Gan et al., 2010) (Figure 4).

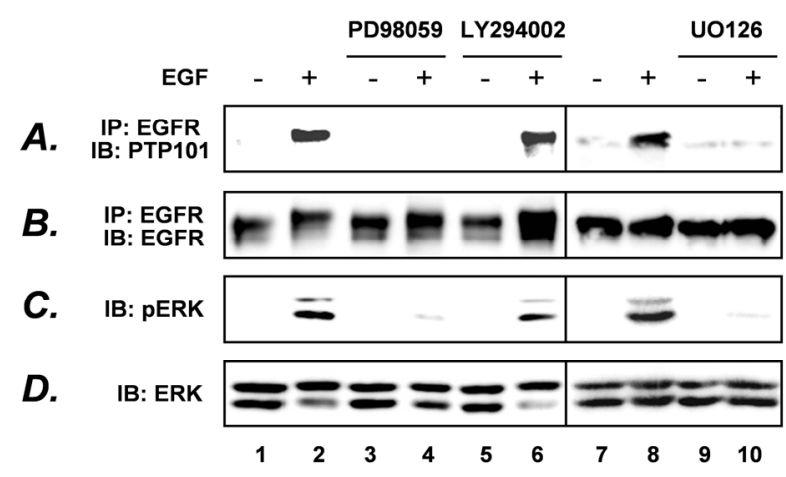

Fig. 4. EGF-induced PTP101-reactive threonine phosphorylation of EGFR is ERK pathway dependent. Serum-starved DU145 cells were pretreated with vehicle control, MEK/ERK pathway inhibitors (PD98059 or UO126) or PI3K/Akt pathway inhibitor (LY294002) for $1 \mathrm{~h}$ prior to stimulation with EGF for $15 \mathrm{~min}$. Protein extracts were either immunoprecipitated (IP) with anti-EGFR antibody, followed by immunoblotting (IB) with PTP101 (A) or antiEGFR $(B)$, or directly immunoblotted with anti-phospho-ERK $(C)$ or anti-total ERK $(D)$. For more details see (Gan et al., 2010). Reprinted with permission from Oncogene.

Two major threonine phosphorylation sites are known in the EGFR juxtamembrane cytoplasmic domain, Thr-654 and Thr-669 (Davis \& Czech, 1985; Heisermann \& Gill, 1988; Hunter et al., 1984; Takishima et al., 1988). PKC may directly mediate Thr-654 phosphorylation (Davis \& Czech, 1985; Hunter et al., 1984), whereas Thr-669 is thought to be phosphorylated by ERKs (Northwood et al., 1991; Takishima et al., 1991). The human EGFR cytoplasmic tail contains only one ERK consensus phosphorylation site [PX(S/T)P], i.e. PL ${ }^{669} \mathrm{TP}$ (Li et al., 2008). In reconstituted Chinese hamster ovary (CHO) cells, we showed that only wild-type EGFR, but not EGFR mutant (EGFR-T669A in which Thr-669 is mutated to alanine), underwent PTP101-reactive phosphorylation upon EGF stimulation, although EGF can cause tyrosine phosphorylation of both forms of receptors ( $\mathrm{Li}$ et al., 2008). In a comparison experiment, in distinction to EGFR-T669A, a different EGFR mutant (EGFRT654A in which Thr-654 is mutated to alanine) can undergo PTP101-reactive phosphorylation after EGF treatment, which was abolished by the MEK/ERK pathway inhibitor PD98059 ( $\mathrm{Li}$ et al., 2008). These findings indicate that Thr-669, but not Thr-654, is required for EGF-induced, ERK activity-dependent PTP101-reactive (threonine) phosphorylation of EGFR. 


\subsection{Impact of Thr-669 phosphorylation on EGFR tyrosine phosphorylation (activation) and trafficking}

EGF binding triggers EGFR kinase activation and phosphorylation, and also initiates the process of EGFR endocytosis and degradation, leading to temporary downregulation of EGFR (Wiley, 2003; Wiley et al., 2003). Previous views held that signaling emanated only from activated cell-surface EGFRs and that internalization terminated signaling (Wells et al., 1990). However, it is now more widely believed that signaling can also emanate from the EGFR in the process of postendocytic trafficking and thus, altered postendocytic trafficking of the activated EGFR may quantitatively and/or qualitatively influence its net signaling (Burke et al., 2001; Ceresa \& Schmid, 2000; Di Fiore \& De Camilli, 2001; Sebastian et al., 2006; Wiley, 2003). We previously reported that GH pretreatment lessens EGF-induced EGFR downregulation in murine 3T3-F442A preadipocytes (Huang et al., 2003). Further, GH-mediated attenuation of EGF-induced EGFR downregulation is ERK pathway-dependent, correlating with GHinduced threonine phosphorylation of EGFR and signaling synergy of GH and EGF (Y. Huang et al., 2004; Huang et al., 2003). Similarly, in human T47D breast carcinoma cells, prolactininduced, ERK activation-dependent, PTP101-reactive phosphorylation of EGFR retards subsequent EGF-induced receptor downregulation and potentiates acute EGF/EGFR signaling (Y. Huang et al., 2006). Furthermore, in T47D cells, EGF itself causes PTP101-reactive threonine phosphorylation of EGFR, and inhibition of the MEK/ERK pathway enhances EGF-induced EGFR downregulation (Y. Huang et al., 2006). Similar results were obtained in a human fibrosarcoma cell line that harbors an activating Ras mutation and subsequent basal activation of ERK and ERK-dependent PTP101-reactive EGFR phosphorylation (Li et al., 2008). Recently, we have demonstrated that in two human prostate cancer cell lines, DU145 and PC-3, pharmacological blockade of MEK/ERK pathway, but not PI3K/Akt pathway, results in accelerated EGF-induced EGFR downregulation (Figure 5), which negatively correlates with ligand-induced ERK-dependent threonine phosphorylation of EGFR (Figure 4) (Gan et al., 2010). Taken together, these results strongly suggest that ERK-mediated threonine phosphorylation of EGFR, whether accomplished by GH or prolactin (via crosstalk), or as a result of EGF-induced ERK activation, may serve as a "brake" on ligand-induced EGFR downregulation. Indeed, elimination of EGFR phosphorylation at threonine- 669 by a point mutation (threonine to alanine) resulted in accelerated EGF-induced EGFR loss in CHO reconstitution cell system (Li et al., 2008).
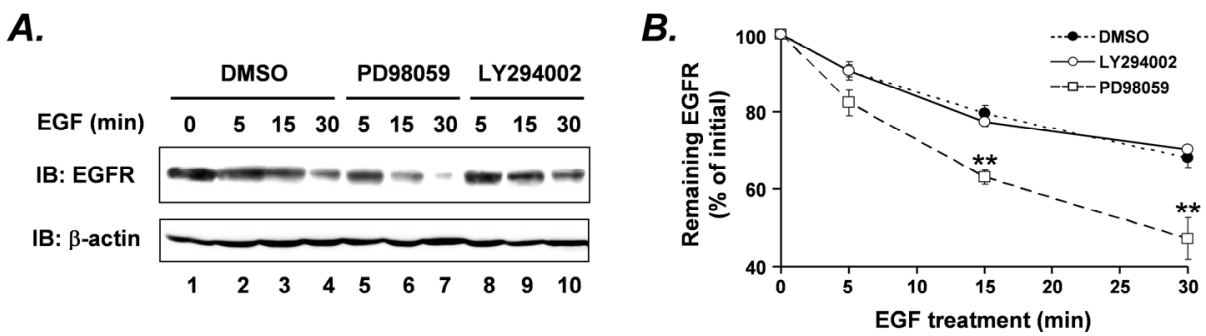

Fig. 5. Inhibition of ERK pathway but not Akt pathway accelerates EGF-induced EGFR downregulation. (A) Serum-starved DU145 cells were pretreated with vehicle (DMSO), PD98059 or LY294002 for $1 \mathrm{~h}$ prior to stimulation with EGF for 0-30 min. Protein extracts were subjected to immunoblotting (IB) with anti-EGFR or anti- $\beta$-actin. (B) Statistical analysis of pooled data from five independent experiments indicated that PD98059 significantly enhances EGF-induced EGFR downregulation at 15 and $30 \mathrm{~min}(* *, P<0.01)$. For more details see (Gan et al., 2010). Reprinted with permission from Oncogene. 
Early studies of EGFR phosphorylation at serine and threonine sites, including serine-1046, serine 1047, and threonine-654, revealed that mutations at these sites can modulate EGFR signaling and downregulation (Bao et al., 2000; Countaway et al., 1990; Countaway et al., 1992; Theroux et al., 1992a). When examining the impact of ERK-mediated EGFR phosphorylation at threonine-669 on EGFR signaling, we found that in the CHO cell reconstitution system, the mutant EGFR-T669A exhibits enhanced tyrosine phosphorylation (reflecting EGFR kinase activation) compared to wild-type EGFR upon EGF stimulation (Li et al., 2008). Interestingly, coexpression of wild-type EGFR and EGFR-T669A, presumably resulting in a hybridimer of wild-type and mutant EGFR, does not dampen the propensity of EGFR-T669A to enhance EGF sensitivity (reflected in enhanced EGFR kinase activation) (Li et al., 2008). This led us to conclude that, in the hybridimer, the mutant EGFR-T669A exerts dominance regarding the EGF-induced EGFR activation (Li et al., 2008). More recently, in human prostate cancer cells (DU145 and PC-3) where the endogenous EGFR level is high, we have shown that pharmacological inhibition of the MEK/ERK pathway, but not the PI3K/Akt pathway, significantly augments the EGF-induced EGFR phosphorylation at multiple tyrosine residues including Y845, Y1045, and Y1068 (Gan et al., 2010).

The EGF-induced downregulation of EGFR is a complex, tightly regulated process, and impaired endocytic downregulation is often associated with malignancy (Grandal \& Madshus, 2008; Polo et al., 2004; Roepstorff et al., 2008). The molecular machinery controlling ligandinduced EGFR endocytic trafficking remains poorly understood. It is believed that ubiquitination plays a key role in "tagging" EGFR for endocytosis. Subsequent to EGF binding to EGFR, the activated receptor is rapidly ubiquitinated by $\mathrm{Cbl}$, an ubiquitin ligase that binds to phosphorylated EGFR, promoting post-internalization EGFR sorting to lysosomes for degradation (see Sections 3.1 and 3.2 for details). In human prostate cancer cells, we uncovered that blockade of the MEK/ERK pathway, but not the PI3K/Akt pathway, significantly enhanced EGF-induced ubiquitination of EGFR, correlating with increased Cbl tyrosine phosphorylation level and degree of physical association between tyrosine phosphorylated $\mathrm{Cbl}$ and activated EGFR (Gan et al., 2010). This phenomenon in prostate cancer cells resembles the effects of mutant EGFR-T669A in the CHO reconstitution system, in which EGFR-T669A underwent more robust ubiquitination than wild-type EGFR did upon EGF stimulation, due to the loss of phosphorylation at Thr-669 in EGFR-T669A cells (Li et al., 2008).

Emerging evidence suggests that $\mathrm{Cbl}$ can bind to EGFR directly at phosphorylated Y1045 or indirectly through Grb2, which binds to phosphorylated Y1068 and Y1086 in the EGFR cytoplasmic tail (Levkowitz et al., 1999; Waterman et al., 2002). As described above, our data in prostate cancer cells indicated that inhibition of ERK activity enhances the EGF-induced tyrosine phosphorylation of EGFR at multiple sites, at least including Y1045 and Y1068 (Gan et al., 2010). This raises several interesting questions, such as through which site(s) or tyrosine residue(s) within the EGFR cytoplasmic domain is the effect of the ERK activation-dependent Thr-669 phosphorylation exerted; whether $\mathrm{Cbl}$ is the sole factor in EGFR ubiquitination or are there any other contributors, such as CIN85, Grb2, Eps15, epsin, Hrs, and ESCRT complexes (see Sections 3.1 and 3.2 for details); and finally whether two completely different types of EGFR phosphorylation (tyrosine versus threonine phosphorylation) exist and how they are balanced under physiological and pathological conditions. More detailed studies are required to decipher these mechanisms. Taken together, our recent experimental data from multiple cell systems strongly support the notion that ERK-mediated Thr-669 phosphorylation of EGFR may serve as a "brake" on EGF-induced EGFR activation, signaling, and trafficking (ubiquitination and downregulation) (Figure 6). 

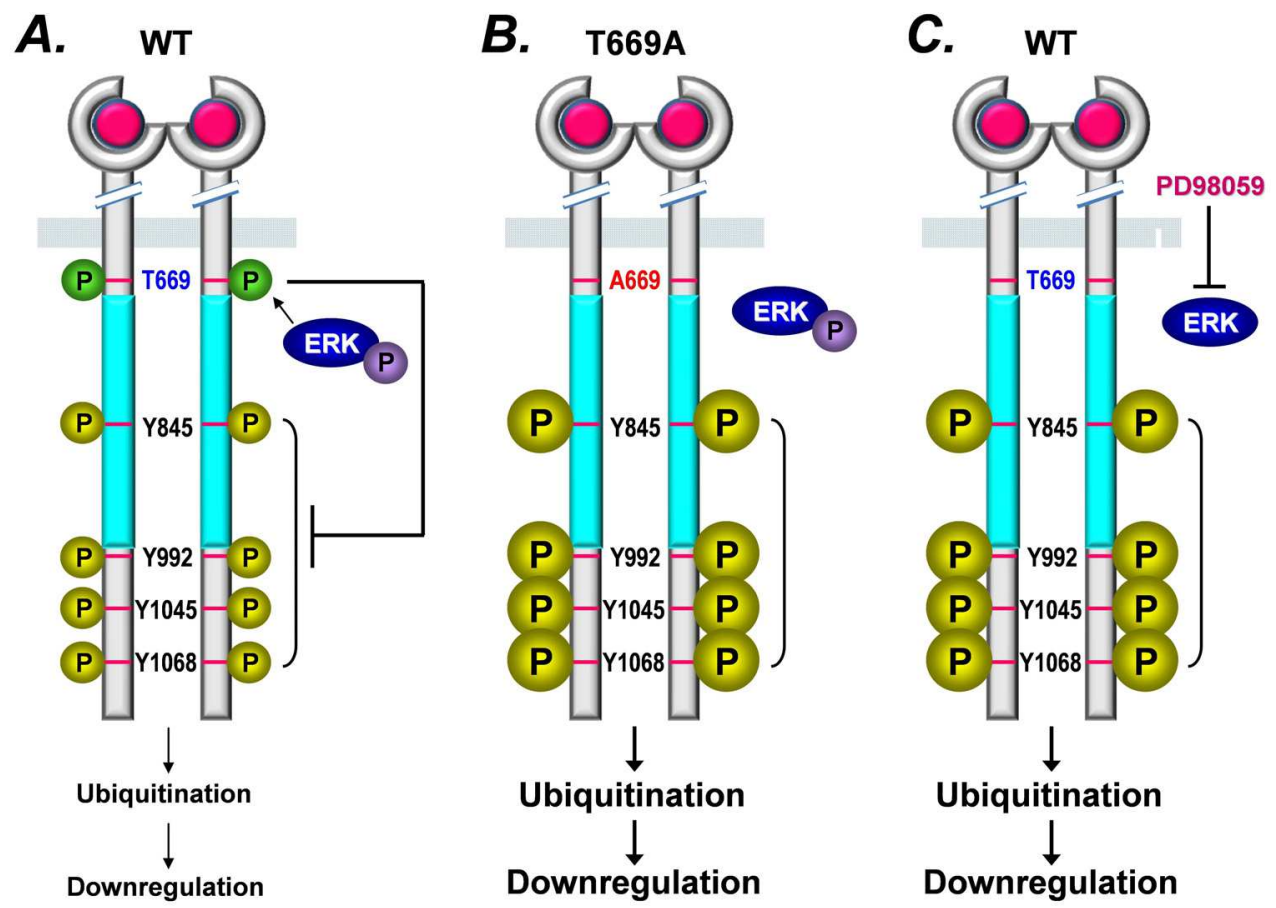

Fig. 6. Schematic model of how ERK activity-dependent threonine phosphorylation of EGFR modulates EGF-induced EGFR ubiquitination and downregulation. Based on our published data (Gan et al., 2010; Huang et al., 2003; Y. Huang et al., 2006; Li et al., 2008), ERK activation results in PTP101-reactive phosphorylation of EGFR at Thr-669. Such threonine phosphorylation serves as a "brake" on EGF-induced EGFR tyrosine phosphorylation (kinase activation), ubiquitination, and downregulation $(A)$. Mutation of Thr-669 to alanine (B), or blockade of the ERK pathway by PD98059 (C) abolishes the threonine phosphorylation of EGFR, which releases the "brake", resulting in enhanced EGF-induced EGFR tyrosine phosphorylation/activation, ubiquitination, and downregulation.

\section{Akt signaling, EGF/EGFR-driven epithelial-mesenchymal transition (EMT) and tumor metastasis}

\subsection{PI3K/Akt signaling pathway}

The PI3K/Akt pathway plays an important role in human cancers including prostate carcinoma (Chin \& Toker, 2009; de Souza et al., 2009; Morgan et al., 2009; Qiao et al., 2008). Akt was initially identified as an oncogene within the murine leukemia virus AKT8 (Staal, 1987; Staal \& Hartley, 1998). It is a serine/threonine kinase and also called protein kinase B (PKB) because its catalytic domain is related to PKA and PKC family members (Jones et al., 1991). In humans, there are three highly homologous isoforms of Akt (Akt1, Akt2, and Akt3) (Nicholson \& Anderson, 2002). However, it remains controversial whether all three are equally important in human malignancies (Chin \& Toker, 2009; Le Page et al., 2006; Maroulakou et al., 2008). PI3K and the tumor suppressor, phosphatase and tensin homolog 
deleted on chromosome 10 (PTEN), are two well-known upstream components of Akt. Receptor tyrosine kinases such as EGFR and IGF-1R can activate PI3K at the cell membrane, initiating the PI3K/Akt signaling cascade. Once activated, PI3K phosphorylates phosphatidylinositol-4,5-diphosphate (PIP2), leading to accumulation of phosphatidylinositol-3,4,5-triphosphate (PIP3) (Morgan et al., 2009). PIP3 recruits Akt and phosphoinositide dependent protein kinase 1 (PDK1) to the cell membrane, where Akt is phosphorylated at Thr-308 by PDK1 and at Ser- 473 via an unknown mechanism (de Souza et al., 2009). Activated Akt translocates to the nucleus, resulting in downstream effects, such as cell survival (anti-apoptosis), cell motility, angiogenesis, proliferation, and metabolism (Chin \& Toker, 2009; de Souza et al., 2009; Morgan et al., 2009). PTEN is the primary negative regulator of Akt ( $\mathrm{Li}$ et al., 1997). Loss of PTEN or PTEN mutation is the most common cause of hyperactivation of the PI3K/Akt pathway in many human cancers (Sansal \& Sellers, 2004). Most recently, we have demonstrated that the Akt pathway plays a central role in EGFR-driven prostate cancer cell migration by activating epithelial-mesenchymal transition (EMT) (Gan et al., 2010), which is discussed in detail below.

\subsection{EMT and tumor metastasis}

EMT is a pivotal physiological process involved in embryogenesis, wound healing, and tissue remodeling (Thiery, 2003), and is regulated by complex signaling networks (Thiery \& Sleeman, 2006). It is now recognized that EMT may be an important mechanism for carcinoma progression given EMT-like phenotypes of epithelial cancers (Klymkowsky \& Savagner, 2009; Thiery, 2002). Acquisition of migratory properties is a prerequisite for cancer progression and for invasive migration of tumor cells into surrounding tissue. Within carcinoma (cancer of epithelial origin) cells, acquisition of invasiveness requires a dramatic morphological alteration similar to EMT, wherein carcinoma cells lose their epithelial characteristics of cell polarity and cell-cell adhesion and switch to a motile mesenchymal phenotype (Thiery, 2002; Thiery, 2003; Thiery \& Sleeman, 2006). Disruption of cell-cell adherens junctions mediated by E-cadherin (one of the epithelial markers) is considered a crucial step in EMT and the downregulation of E-cadherin is common in metastatic carcinomas (Cavallaro \& Christofori, 2004). Reduced E-cadherin expression has been found in high-grade prostate cancers and is associated with poor prognosis (Umbas et al., 1994; Umbas et al., 1992), reflective of its critical role in tumor progression. It is widely believed that downregulation of E-cadherin occurs via transcriptional repression mediated by the protein, Snail (Cano et al., 2000; Moreno-Bueno et al., 2008; Peinado et al., 2007). Accumulating evidence indicates that the EGFR family and PI3K/Akt signaling pathway can regulate Snail expression (Hipp et al., 2009; Lee et al., 2008; Qiao et al., 2008), suggesting that inhibition of the EGFR signaling pathways may prevent the loss of E-cadherin function and thereby acquisition of invasive motility (metastasis).

\subsection{Role of Akt signaling in EGF/EGFR-driven EMT and prostate cancer cell migration}

To understand which pathway(s) may have significant impact on EGFR-driven migration, we have recently probed this issue in human prostate cancer cells. The two cell lines, DU145 and PC-3, are both androgen insensitive (van Bokhoven et al., 2003), and are excellent models for studying EGFR signaling in hormonal-refractory prostate cancer. We showed that the two cell lines predominantly expressed EGFR but not ErbB-2 when compared to an androgen-responsive prostate cancer cell line, LnCap (van Bokhoven et al., 2003), in which 
both EGFR and ErbB-2 were expressed (Gan et al., 2010). EGF activated EGFR and its downstream ERK and Akt pathways, and markedly promoted cell migration in both DU145 and PC-3. Using pharmacological inhibitors, LY294002 and PD98059, to specifically block PI3K/Akt and MEK/ERK pathways, respectively, we further demonstrated that LY29004, but not PD98059, significantly inhibited EGF/EGFR-driven cell motility. In parallel, we observed that DU145 cells expressing constitutively activated (myristoylated) Akt (Myr-Akt) migrated much faster than control cells (Gan et al., 2010). Taken together, our data suggests that Akt activation is critical for EGFR-mediated prostate cancer cell migration.

As described above, tumors of epithelial origin, as they transform to malignancy, appear to exploit the innate plasticity of epithelial cells, with EMT conferring increased invasiveness and metastatic potential. Previous studies have implicated the involvement of ErbBs in EMT and E-cadherin downregulation in breast, lung, and cervical cancer cells (Lee et al., 2008; Lu et al., 2009; Z. Lu et al., 2003). Our recent work has clearly demonstrated that prostate cancer cells undergo EMT-like morphological changes after EGF treatment, accompanied by the loss of E-cadherin at cell-cell junctions (Gan et al., 2010). Interestingly, these EGF-induced phenomena were markedly prevented when the cells were exposed to the PI3K/Akt pathway inhibitor LY294002 (Figure 7). Consistent with downregulation of E-cadherin (an epithelial marker), we further showed an upregulation of vimentin (a mesenchymal marker) induced by EGF treatment. Similarly, LY294002 pretreatment abolished the EGF-induced quantitative (mass) changes of both E-cadherin and vimentin (Figure 8) (Gan et al., 2010). All these findings suggest that Akt activation is required for EGFR-driven EMT.
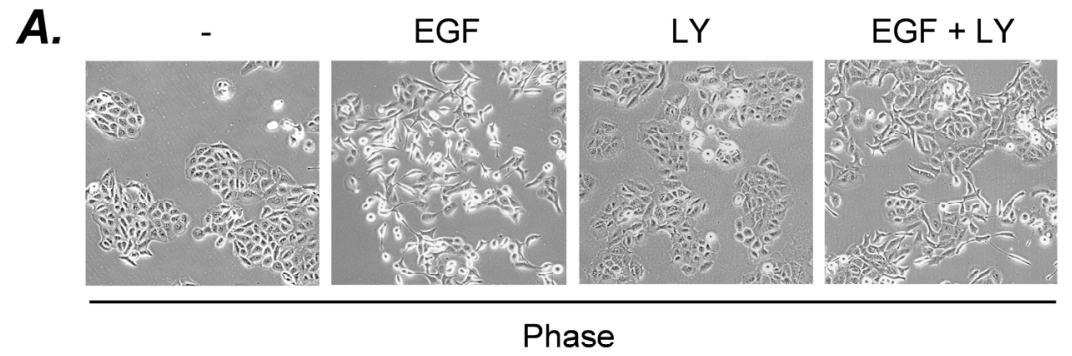

Phase

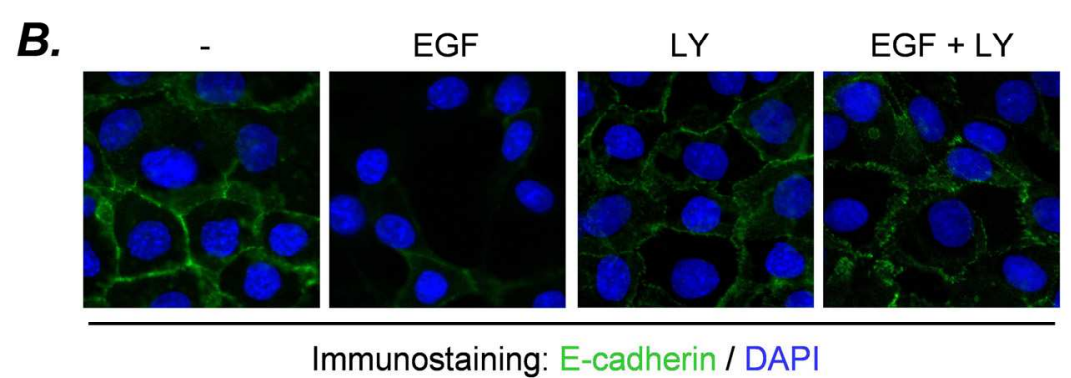

Fig. 7. Effect of inhibition of Akt pathway on EGF-induced EMT and loss of E-cadherin at cell-cell junction. Serum-starved DU145 cells were treated with vehicle (-) or EGF for $24 \mathrm{~h}$ in the presence or absence of LY294002. Inhibition of the Akt pathway by LY294002 prevents EGF-induced EMT $(A)$ and loss of E-cadherin expression at cell-cell adherens junctions $(B)$. For details see (Gan et al., 2010). Reprinted with permission from Oncogene. 
A.
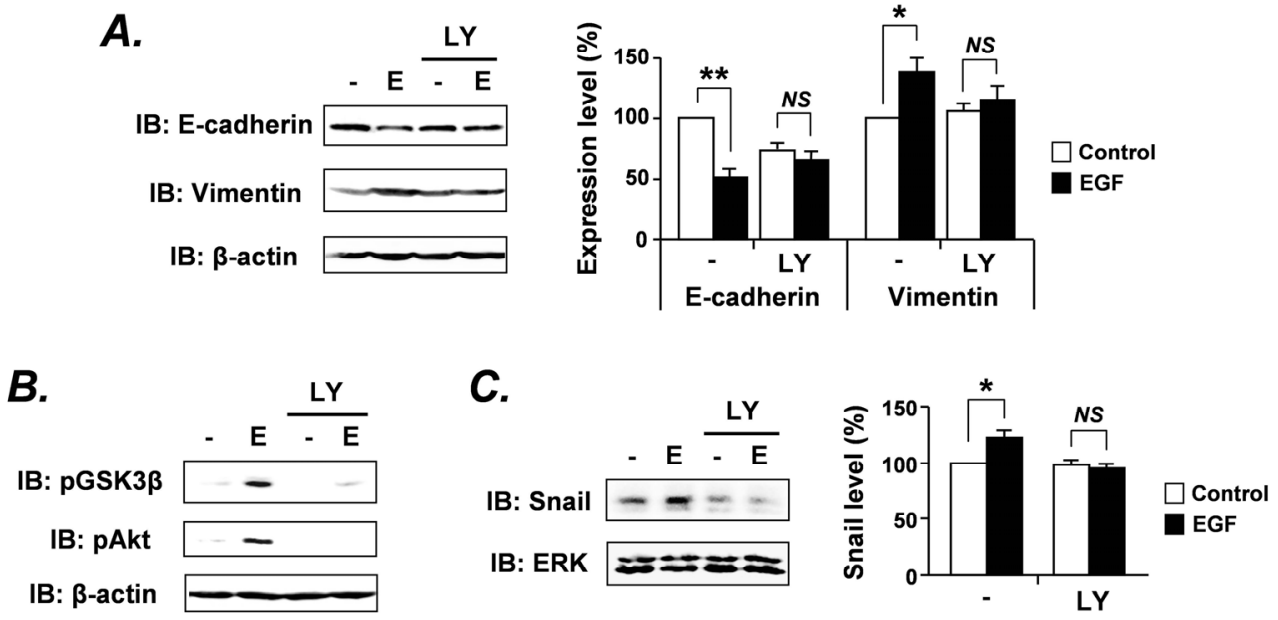

Fig. 8. Akt signaling contributes to EGF-driven EMT through the route of EGFR $\rightarrow$ Akt $\rightarrow$ GSK3 $\beta \rightarrow$ Snail $\rightarrow$ E-cadherin. $(A)$ LY294002 abolishes EGF-induced downregulation of E-cadherin and upregulation of vimentin. (B) LY294002 prevents EGFinduced phosphorylation (inactivation) of GSK3 $\beta$ via Akt inhibition. (C) LY294002 blocks EGF-induced upregulation of Snail. ${ }^{*}, P<0.05 ;{ }^{* *}, P<0.01 ; N S$, not statistically significant. For details see (Gan et al., 2010). Reprinted with permission from Oncogene.

Snail is one of the several transcriptional factors that can suppress E-cadherin gene expression (Batlle et al., 2000; Cano et al., 2000) via binding to E-box sequences in the proximal E-cadherin promoter (Hemavathy et al., 2000). Snail is regulated by glycogen synthase kinase $3 \beta$ (GSK3 $\beta$, a downstream effector of Akt) by direct binding and phosphorylation, and inhibition of GSK3 $\beta$ results in upregulation of Snail and downregulation of E-cadherin (Zhou et al., 2004). This implies that Snail and GSK3 $\beta$ together, function as a molecular switch for many signaling pathways leading to EMT, and may provide a new connection of Akt to EMT. Along this line, we uncovered that in prostate cancer cells, EGF induced robust GSK3 $\beta$ phosphorylation (inactivation) and LY294002 markedly inhibited this phosphorylation, which correlated with the Akt activity. Consistent with Akt-mediated inactivation of GSK3 $\beta$, Snail was upregulated upon EGF stimulation. Intriguingly, LY294002 pretreatment abolished such an EGF-induced upregulation of Snail, presumably by inactivating Akt and restoring GSK3 $\beta$ activity (Figure 8 ). As an alternative approach, we also demonstrated that knockdown of endogenous Snail in DU145 cells significantly prevented the EGF-induced loss of E-cadherin expression and concomitantly suppressed EGF-driven EMT, which correlated with a decrease in EGFdirected cell migration (Figure 9) (Gan et al., 2010). These results implicate Snail as a central effector of EMT and cell motility mediated by EGF/EGFR-activated Akt within prostate cancer cells. Collectively, our findings that EGF-mediated Akt signaling affects both phenotypic and molecular attributes, typical of EMT, provide new insights into the molecular mechanisms of EGFR-driven prostate cancer progression and metastasis. 
A.

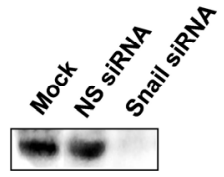

IB: $\beta$-actin

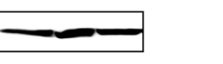

B.

IB: E-cadherin

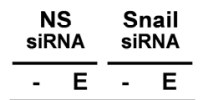

IB: $\beta$-actin

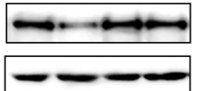

C.
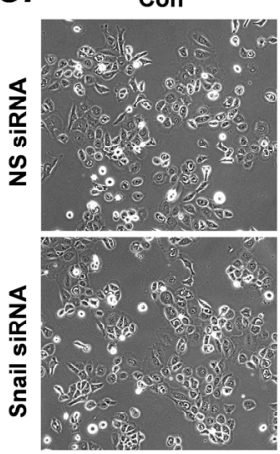

EGF
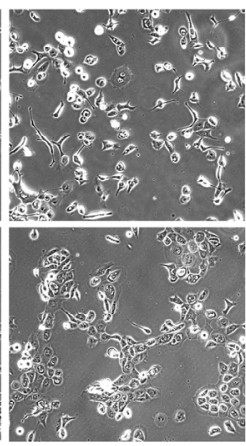

D.

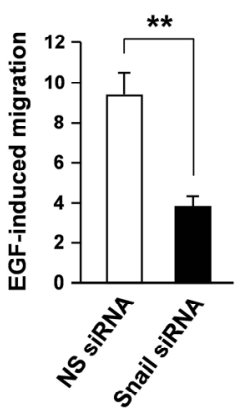

Fig. 9. Knockdown of endogenous Snail prevents EGF-induced E-cadherin loss, EMT, and cell migration. (A) Knockdown of Snail in DU145 cells. (B) Knockdown of Snail prevents EGF-induced loss of E-cadherin expression. (C) Knockdown of Snail blocks EGF-induced EMT process. $(D)$ Knockdown of Snail reduces EGF-driven cell migration measured by transwell assay. NS siRNA, nonspecific siRNA (control); ${ }^{* *}, P<0.01$. For details see (Gan et al., 2010). Reprinted with permission from Oncogene.

\section{Negative feedback loop between EGFR-directed ERK and Akt signaling}

As described above, Ras/Raf/MEK/ERK and PI3K/Akt signaling pathways play central roles in many aspects related to tumorigenesis and cancer progression. Thus, inhibition of these signaling cascades could hold powerful therapeutic potentials. Given that many receptors utilize the common downstream pathways such as MEK/ERK and PI3K/Akt, targeting these kinases is expected to have greater therapeutic efficacy and broader applicability. For example, blockade of signaling through MEK offers the potential advantage of inhibiting both proliferation-promoting and anti-apoptotic signals originating from either activated receptors or mutation of RAS/Raf in breast cancer (Adeyinka et al., 2002). However, clinical studies of MEK inhibitors have only shown limited antitumor effects (Adjei et al., 2008; Rinehart et al., 2004). The underlying mechanisms remain poorly understood.

The molecular features of breast cancer cells that determine sensitivity to pharmacological inhibition of the Ras/Raf/MEK/ERK signaling pathway have been recently examined. Using a large set of human breast cancer cell lines as a model system, it was found that activation of PI3K/Akt pathway in response to MEK inhibition through a negative MEKEGFR-PI3K feedback loop counteracts the efficacy of MEK inhibition on cell cycle and apoptosis induction (Mirzoeva et al., 2009). In concert with this finding, we uncovered that in prostate cancer cells, in contrast to inhibition of PI3K/Akt pathway, inhibition of MEK/ERK pathway rather enhanced EGF-directed cell motility, accompanied by enhanced EGF-induced Akt activation (Figure 10) (Gan et al., 2010). This phenomenon highly supports the notion that Akt is the key node in EGFR-mediated migratory pathways (see Section 5.3). It also raises a key question as to how ERK inactivation exerts its feedback effect to EGFinduced Akt activation. Based on our data, we believe that one mechanism could be through the feedback of ERK on EGFR phosphorylation (Figure 6). One can envision that inhibition 
of ERK activity eliminates EGFR threonine-669 phosphorylation, resulting in enhanced EGFR tyrosine phosphorylation (kinase activation), and subsequently augmented activation of the downstream PI3K/Akt pathway. The discovery of the negative feedback loop of MEK/ERK-EGFR-PI3K/Akt on several cellular aspects implies that targeting single MEK/ERK pathway in some cancers (e.g., breast and prostate carcinomas) may have undesirable outcomes, which deserves further investigation.

A.

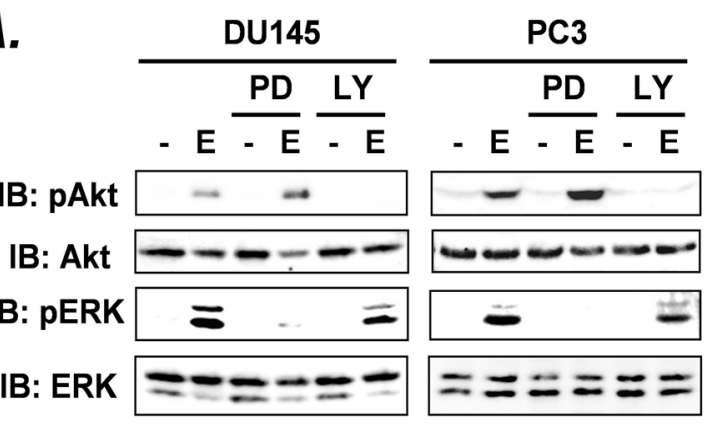

B.

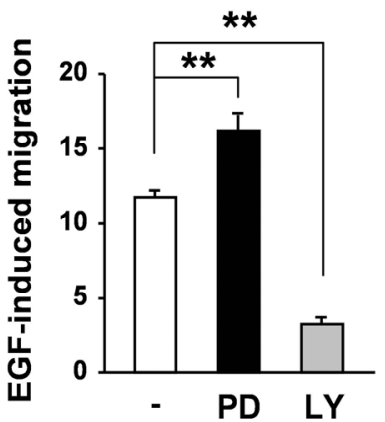

Fig. 10. Effects of ERK and Akt pathways on EGF-driven prostate cancer cell migration. $(A)$ Inhibition of the ERK pathway by PD98059 augments EGF-induced Akt activation in both DU145 and PC3 cells, revealed by immunoblotting (IB) with anti-phospho-Akt antibody (top panel). (B) Transwell assay shows that blockade of the Akt pathway by LY294002 significantly inhibits EGF-driven cell migration. In contrast, blockade of the ERK pathway by PD98059 rather enhances EGF-induced migration. **, $P<0.01$. For details see (Gan et al., 2010). Reprinted with permission from Oncogene.

\section{Concluding remarks}

Recent advances in the ErbB field have broadened our understanding of the important roles of EGFR/ErbB signaling in human cancer. However, the complexity of the ErbB signaling network, which involves numerous ligands, multiple dimerization partners, and a variety of downstream signaling components, makes it a real challenge to establish which pathways are activated or critical in the context of tumorigenesis and progression of specific cancer types. In this chapter, several aspects of EGFR/ErbB signaling and their potential roles in prostate cancer initiation and progression are discussed. In particular, we focus on the mechanisms of how Ras/Raf/MEK/ERK and PI3K/Akt pathways impact EGFR phosphorylation, trafficking, and cell motility. New insights into prostate cancer biology gained from our own work and the studies of other investigators highlight the importance of ERK activity-dependent threonine- 669 phosphorylation of EGFR and its profound feedback on EGFR tyrosine phosphorylation/kinase activation, ubiquitination, and trafficking. Recent data from our group demonstrates that the Akt pathway plays a pivotal role in EGFR-driven prostate cancer cell migration by activating EMT. In particular, our results in prostate cancer (Gan et al., 2010) and data from a recent study in breast cancer (Mirzoeva et al., 2009) suggest that therapeutic targeting of ERK signaling may have undesirable outcomes. For example, inhibition of the MEK/ERK pathway conversely 
activates the PI3K/Akt pathway through a negative MEK/ERK-EGFR-PI3K/Akt feedback loop. We believe that ERK-mediated threonine-669 phosphorylation is critically involved in such a negative feedback and thereby contributes to invasive migration (metastasis). Thus, inhibition of the MEK/ERK-EGFR-PI3K/Akt feedback loop is likely to result in therapeutic synergism. Future detailed studies along these lines and a deeper understanding of various mechanisms of cell signaling from EGFR and other ErbBs will undoubtedly generate new avenues for drug and biomarker development to combat cancers including prostate cancer.

\section{Acknowledgments}

This work was supported by a St. Joseph's Foundation (SJF) Startup Fund, an American Heart Association (AHA) Beginning Grant-in-Aid Award, and a Science Foundation Arizona (SFAz) Competitive Advantage Award (to $\mathrm{YH}$ ). The authors have nothing to disclose. Correspondence should be addressed to Dr. Yao Huang, 445 N 5th Street, Suite 110, Phoenix, Arizona, 85004, USA. E-mail: yhuang@chw.edu.

\section{References}

Adams, T.E.; McKern, N.M. \& Ward, C.W. (2004). Signaling by the type 1 insulin-like growth factor receptor: interplay with the epidermal growth factor receptor. Growth Factors, 22:89-95.

Adeyinka, A.; Nui, Y.; Cherlet, T.; Snell, L.; Watson, P.H. \& Murphy, L.C. (2002). Activated mitogen-activated protein kinase expression during human breast tumorigenesis and breast cancer progression. Clin Cancer Res, 8:1747-53.

Adjei, A.A.; Cohen, R.B.; Franklin, W.; Morris, C.; Wilson, D.; Molina, J.R.; Hanson, L.J.; Gore, L.; Chow, L.; Leong, S.; Maloney, L.; Gordon, G.; Simmons, H.; Marlow, A.; Litwiler, K.; Brown, S.; Poch, G.; Kane, K.; Haney, J. \& Eckhardt, S.G. (2008). Phase I pharmacokinetic and pharmacodynamic study of the oral, small-molecule mitogenactivated protein kinase kinase 1/2 inhibitor AZD6244 (ARRY-142886) in patients with advanced cancers. J Clin Oncol, 26:2139-46.

Alroy, I. \& Yarden, Y. (1997). The ErbB signaling network in embryogenesis and oncogenesis: signal diversification through combinatorial ligand-receptor interactions. FEBS Lett, 410:83-6.

Andl, C.D.; Mizushima, T.; Oyama, K.; Bowser, M.; Nakagawa, H. \& Rustgi, A.K. (2004). EGFR-induced cell migration is mediated predominantly by the JAK-STAT pathway in primary esophageal keratinocytes. Am J Physiol Gastrointest Liver Physiol, 287:G1227-37.

Baass, P.C.; Di Guglielmo, G.M.; Authier, F.; Posner, B.I. \& Bergeron, J.J. (1995). Compartmentalized signal transduction by receptor tyrosine kinases. Trends Cell Biol, 5:465-70.

Bache, K.G.; Raiborg, C.; Mehlum, A. \& Stenmark, H. (2003). STAM and Hrs are subunits of a multivalent ubiquitin-binding complex on early endosomes. I Biol Chem, 278:12513-21.

Bache, K.G.; Stuffers, S.; Malerød, L.; Slagsvold, T.; Raiborg, C.; Lechardeur, D.; Wälchli, S.; Lukacs, G.L.; Brech, A. \& Stenmark, H. (2006). The ESCRT-III subunit hVps24 is 
required for degradation but not silencing of the epidermal growth factor receptor. Mol Biol Cell, 17:2513-23.

Bao, J.; Alroy, I.; Waterman, H.; Schejter, E.D.; Brodie, C.; Gruenberg, J. \& Yarden, Y. (2000). Threonine phosphorylation diverts internalized epidermal growth factor receptors from a degradative pathway to the recycling endosome. J Biol Chem, 275:26178-86.

Baselga, J. \& Hammond, L.A. (2002). HER-targeted tyrosine-kinase inhibitors. Oncology, 63:6-16.

Batlle, E.; Sancho, E.; Francí, C.; Domínguez, D.; Monfar, M.; Baulida, J. \& García De Herreros, A. (2000). The transcription factor snail is a repressor of E-cadherin gene expression in epithelial tumour cells. Nat Cell Biol, 2:84-9.

Batzer, A.G.; Rotin, D.; Ureña, J.M.; Skolnik, E.Y. \& Schlessinger, J. (1994). Hierarchy of binding sites for Grb2 and Shc on the epidermal growth factor receptor. Mol Cell Biol, 14:5192-201.

Bild, A.H.; Turkson, J. \& Jove, R. (2002). Cytoplasmic transport of Stat3 by receptormediated endocytosis. EMBO J, 21:3255-63.

Burke, P.; Schooler, K. \& Wiley, H.S. (2001). Regulation of epidermal growth factor receptor signaling by endocytosis and intracellular trafficking. Mol Biol Cell, 12:1897-910.

Cai, C.Q.; Peng, Y.; Buckley, M.T.; Wei, J.; Chen, F.; Liebes, L.; Gerald, W.L.; Pincus, M.R.; Osman, I. \& Lee, P. (2008). Epidermal growth factor receptor activation in prostate cancer by three novel missense mutations. Oncogene, 27:3201-10.

Cano, A.; Pérez-Moreno, M.A.; Rodrigo, I.; Locascio, A.; Blanco, M.J.; del Barrio, M.G.; Portillo, F. \& Nieto, M.A. (2000). The transcription factor snail controls epithelialmesenchymal transitions by repressing E-cadherin expression. Nat Cell Biol, 2:76-83.

Carpenter, G. (2000). The EGF receptor: a nexus for trafficking and signaling. Bioessays, 22:697-707.

Cavallaro, U. \& Christofori, G. (2004). Cell adhesion and signalling by cadherins and IgCAMs in cancer. Nat Rev Cancer, 4:118-32.

Ceresa, B.P. \& Schmid, S.L. (2000). Regulation of signal transduction by endocytosis. Curr Opin Cell Biol, 12:204-10.

Chen, C. \& Zhuang, X. (2008). Epsin 1 is a cargo-specific adaptor for the clathrin-mediated endocytosis of the influenza virus. Proc Natl Acad Sci U S A, 105:11790-5.

Chin, Y.R. \& Toker, A. (2009). Function of Akt/PKB signaling to cell motility, invasion and the tumor stroma in cancer. Cell Signal, 21:470-6.

Ciardiello, F. \& Tortora, G. (2003). Epidermal growth factor receptor (EGFR) as a target in cancer therapy: understanding the role of receptor expression and other molecular determinants that could influence the response to anti-EGFR drugs. Eur J Cancer, 39:1348-54.

Citri, A. \& Yarden, Y. (2006). EGF-ERBB signalling: towards the systems level. Nat Rev Mol Cell Biol, 7:505-16.

Countaway, J.L.; McQuilkin, P.; Girones, N. \& Davis, R.J. (1990). Multisite phosphorylation of the epidermal growth factor receptor. Use of site-directed mutagenesis to examine the role of serine/threonine phosphorylation. J Biol Chem, 265:3407-16.

Countaway, J.L.; Nairn, A.C. \& Davis, R.J. (1992). Mechanism of desensitization of the epidermal growth factor receptor protein-tyrosine kinase. J Biol Chem, 267:1129-40. 
Craft, N.; Shostak, Y.; Carey, M. \& Sawyers, C.L. (1999). A mechanism for hormoneindependent prostate cancer through modulation of androgen receptor signaling by the HER-2/neu tyrosine kinase. Nat Med, 5:280-5.

Davis, R.J. \& Czech, M.P. (1985). Tumor-promoting phorbol diesters cause the phosphorylation of epidermal growth factor receptors in normal human fibroblasts at threonine-654. Proc Natl Acad Sci U S A, 82:1974-8.

Davis, R.J. \& Czech, M.P. (1987). Stimulation of epidermal growth factor receptor threonine 654 phosphorylation by platelet-derived growth factor in protein kinase C-deficient human fibroblasts. J Biol Chem, 262:6832-41.

de Souza, P.L.; Russell, P.J. \& Kearsley, J. (2009). Role of the Akt pathway in prostate cancer. Curr Cancer Drug Targets, 9:163-75.

DeHaan, A.M.; Wolters, N.M.; Keller, E.T. \& Ignatoski, K.M. (2009). EGFR ligand switch in late stage prostate cancer contributes to changes in cell signaling and bone remodeling. Prostate, 69:528-37.

Dhillon, A.S.; Hagan, S.; Rath, O. \& Kolch, W. (2007). MAP kinase signalling pathways in cancer. Oncogene, 26:3279-90.

Di Fiore, P.P. \& De Camilli, P. (2001). Endocytosis and signaling. an inseparable partnership. Cell, 106:1-4.

Di Guglielmo, G.M.; Baass, P.C.; Ou, W.J.; Posner, B.I. \& Bergeron, J.J. (1994). Compartmentalization of SHC, GRB2 and mSOS, and hyperphosphorylation of Raf-1 by EGF but not insulin in liver parenchyma. Embo J, 13:4269-77.

Djakiew, D. (2000). Dysregulated expression of growth factors and their receptors in the development of prostate cancer. Prostate, 42:150-60.

Douglas, D.A.; Zhong, H.; Ro, J.Y.; Oddoux, C.; Berger, A.D.; Pincus, M.R.; Satagopan, J.M.; Gerald, W.L.; Scher, H.I.; Lee, P. \& Osman, I. (2006). Novel mutations of epidermal growth factor receptor in localized prostate cancer. Front Biosci, 11:2518-25.

Downward, J. (1996). Control of ras activation. Cancer Surv, 27:87-100.

Duan, L.; Miura, Y.; Dimri, M.; Majumder, B.; Dodge, I.L.; Reddi, A.L.; Ghosh, A.; Fernandes, N.; Zhou, P.; Mullane-Robinson, K.; Rao, N.; Donoghue, S.; Rogers, R.A.; Bowtell, D.; Naramura, M.; Gu, H.; Band, V. \& Band, H. (2003). Cbl-mediated ubiquitinylation is required for lysosomal sorting of epidermal growth factor receptor but is dispensable for endocytosis. J Biol Chem, 278:28950-60.

Dunn, K.L.; Espino, P.S.; Drobic, B.; He, S. \& Davie, J.R. (2005). The Ras-MAPK signal transduction pathway, cancer and chromatin remodeling. Biochem Cell Biol, 83:1-14.

Elson, S.D.; Browne, C.A. \& Thorburn, G.D. (1984). Identification of epidermal growth factor-like activity in human male reproductive tissues and fluids. J Clin Endocrinol Metab, 58:589-94.

Epstein, R.J.; Druker, B.J.; Roberts, T.M. \& Stiles, C.D. (1990). Modulation of a Mr 175,000 c-neu receptor isoform in G8/DHFR cells by serum starvation. J Biol Chem, 265:10746-51.

Feshchenko, E.A.; Langdon, W.Y. \& Tsygankov, A.Y. (1998). Fyn, Yes, and Syk phosphorylation sites in $\mathrm{c}-\mathrm{Cbl}$ map to the same tyrosine residues that become phosphorylated in activated T cells. J Biol Chem, 273:8323-31.

Freeman, M.R.; Paul, S.; Kaefer, M.; Ishikawa, M.; Adam, R.M.; Renshaw, A.A.; Elenius, K. \& Klagsbrun, M. (1998). Heparin-binding EGF-like growth factor in the human 
prostate: synthesis predominantly by interstitial and vascular smooth muscle cells and action as a carcinoma cell mitogen. J Cell Biochem, 68:328-38.

Gan, Y.; Shi, C.; Inge, L.; Hibner, M.; Balducci, J. \& Huang, Y. (2010). Differential roles of ERK and Akt pathways in regulation of EGFR-mediated signaling and motility in prostate cancer cells. Oncogene, 29:4947-58.

Gee, J.M.; Robertson, J.F.; Gutteridge, E.; Ellis, I.O.; Pinder, S.E.; Rubini, M. \& Nicholson, R.I. (2005). Epidermal growth factor receptor/HER2/insulin-like growth factor receptor signaling and oestrogen receptor activity in clinical breast cancer. Endocr Relat Cancer, 12:S99-S111.

Goh, L.K.; Huang, F.; Kim, W.; Gygi, S. \& Sorkin, A. (2010). Multiple mechanisms collectively regulate clathrin-mediated endocytosis of the epidermal growth factor receptor. J Cell Biol, 189:871-83.

Grandal, M.V. \& Madshus, I.H. (2008). Epidermal growth factor receptor and cancer: control of oncogenic signalling by endocytosis. J Cell Mol Med, 12:1527-34.

Graus-Porta, D.; Beerli, R.R.; Daly, J.M. \& Hynes, N.E. (1997). ErbB-2, the preferred heterodimerization partner of all ErbB receptors, is a mediator of lateral signaling. Embo J, 16:1647-55.

Grøvdal, L.M.; Stang, E.; Sorkin, A. \& Madshus, I.H. (2004). Direct interaction of Cbl with pTyr 1045 of the EGF receptor (EGFR) is required to sort the EGFR to lysosomes for degradation. Exp Cell Res, 300:388-95.

Guy, P.M.; Platko, J.V.; Cantley, L.C.; Cerione, R.A. \& Carraway, K.L. (1994). Insect cellexpressed p180erbB3 possesses an impaired tyrosine kinase activity. Proc Natl Acad Sci U S A, 91:8132-6.

Harari, D.; Tzahar, E.; Romano, J.; Shelly, M.; Pierce, J.H.; Andrews, G.C. \& Yarden, Y. (1999). Neuregulin-4: a novel growth factor that acts through the ErbB-4 receptor tyrosine kinase. Oncogene, 18:2681-9.

Harari, P. (2004). Epidermal growth factor receptor inhibition strategies in oncology. Endocr Relat Cancer, 11:689-708.

Hatake, K.; Tokudome, N. \& Ito, Y. (2007). Next generation molecular targeted agents for breast cancer: focus on EGFR and VEGFR pathways. Breast Cancer, 14:132-49.

Haugh, J.M. \& Meyer, T. (2002). Active EGF receptors have limited access to PtdIns $(4,5) \mathrm{P}(2)$ in endosomes: implications for phospholipase C and PI 3-kinase signaling. J Cell Sci, 115:303-10.

He, M. \& Young, C.Y. (2009). Mutant epidermal growth factor receptor vIII increases cell motility and clonogenecity in a prostate cell line RWPE1. J Endocrinol Invest, 32:272-8.

Heisermann, G.J. \& Gill, G.N. (1988). Epidermal growth factor receptor threonine and serine residues phosphorylated in vivo. J Biol Chem, 263:13152-8.

Hemavathy, K.; Ashraf, S.I. \& Ip, Y.T. (2000). Snail/slug family of repressors: slowly going into the fast lane of development and cancer. Gene, 257:1-2.

Hicke, L. (1999). Gettin' down with ubiquitin: turning off cell-surface receptors, transporters and channels. Trends Cell Biol, 9:107-12.

Hipp, S.; Walch, A.; Schuster, T.; Losko, S.; Laux, H.; Bolton, T.; Höfler, H. \& Becker, K.F. (2009). Activation of epidermal growth factor receptor results in Snail protein but not mRNA over-expression in endometrial cancer. J Cell Mol Med:, 13:3858-67. 
Hirsch, F.R.; Scagliotti, G.V.; Langer, C.J.; Varella-Garcia, M. \& Franklin, W.A. (2003). Epidermal growth factor family of receptors in preneoplasia and lung cancer: perspectives for targeted therapies. Lung Cancer, 41:S29-42.

Hofer, D.R.; Sherwood, E.R.; Bromberg, W.D.; Mendelsohn, J.; Lee, C. \& Kozlowski, J.M. (1991). Autonomous growth of androgen-independent human prostatic carcinoma cells: role of transforming growth factor alpha. Cancer Res, 51:2780-5.

Huang, F.; Goh, L.K. \& Sorkin, A. (2007). EGF receptor ubiquitination is not necessary for its internalization. Proc Natl Acad Sci U S A, 104:16904-9.

Huang, F.; Khvorova, A.; Marshall, W. \& Sorkin, A. (2004). Analysis of clathrin-mediated endocytosis of epidermal growth factor receptor by RNA interference. J Biol Chem, 279:16657-61.

Huang, F.; Kirkpatrick, D.; Jiang, X.; Gygi, S. \& Sorkin, A. (2006). Differential regulation of EGF receptor internalization and degradation by multiubiquitination within the kinase domain. Mol Cell, 21:737-48.

Huang, F. \& Sorkin, A. (2005). Growth factor receptor binding protein 2-mediated recruitment of the RING domain of $\mathrm{Cbl}$ to the epidermal growth factor receptor is essential and sufficient to support receptor endocytosis. Mol Biol Cell, 16:1268-81.

Huang, P.H.; Xu, A.M. \& White, F.M. (2009). Oncogenic EGFR signaling networks in glioma. Sci Signal, 2:re6.

Huang, Y.; Chang, Y.; Wang, X.; Jiang, J. \& Frank, S.J. (2004). Growth hormone alters epidermal growth factor receptor binding affinity via activation of ERKs in 3T3F442A cells. Endocrinology, 145:3297-306.

Huang, Y.; Kim, S.O.; Jiang, J. \& Frank, S.J. (2003). Growth hormone-induced phosphorylation of epidermal growth factor (EGF) receptor in 3T3-F442A cells. Modulation of EGF-induced trafficking and signaling. J Biol Chem, 278:18902-13.

Huang, Y.; Li, X.; Jiang, J. \& Frank, S.J. (2006). Prolactin modulates phosphorylation, signaling and trafficking of epidermal growth factor receptor in human T47D breast cancer cells. Oncogene, 25:7565-76.

Hunter, T.; Ling, N. \& Cooper, J.A. (1984). Protein kinase C phosphorylation of the EGF receptor at a threonine residue close to the cytoplasmic face of the plasma membrane. Nature, 311:480-3.

Jiang, X.; Huang, F.; Marusyk, A. \& Sorkin, A. (2003). Grb2 regulates internalization of EGF receptors through clathrin-coated pits. Mol Biol Cell, 14:858-70.

Jiang, X. \& Sorkin, A. (2003). Epidermal growth factor receptor internalization through clathrin-coated pits requires Cbl RING finger and proline-rich domains but not receptor polyubiquitylation. Traffic, 4:529-43.

Johnson, G.L.; Dohlman, H.G. \& Graves, L.M. (2005). MAPK kinase kinases (MKKKs) as a target class for small-molecule inhibition to modulate signaling networks and gene expression. Curr Opin Chem Biol, 9:325-31.

Jones, P.F.; Jakubowicz, T.; Pitossi, F.J.; Maurer, F. \& Hemmings, B.A. (1991). Molecular cloning and identification of a serine/threonine protein kinase of the secondmessenger subfamily. Proc Natl Acad Sci U S A, 88:4171-5.

Katzmann, D.J.; Odorizzi, G. \& Emr, S.D. (2002). Receptor downregulation and multivesicular-body sorting. Nat Rev Mol Cell Biol, 3:893-905. 
Kim, H.G.; Kassis, J.; Souto, J.C.; Turner, T. \& Wells, A. (1999). EGF receptor signaling in prostate morphogenesis and tumorigenesis. Histol Histopathol, 14:1175-82.

Kloth, M.T.; Catling, A.D. \& Silva, C.M. (2002). Novel activation of STAT5b in response to epidermal growth factor. J Biol Chem, 277:8693-701.

Klymkowsky, M.W. \& Savagner, P. (2009). Epithelial-mesenchymal transition: a cancer researcher's conceptual friend and foe. Am J Pathol, 174:1588-93.

Lai, W.H.; Cameron, P.H.; Doherty, J.J.; Posner, B.I. \& Bergeron, J.J. (1989). Ligand-mediated autophosphorylation activity of the epidermal growth factor receptor during internalization. J Cell Biol, 109:2751-60.

Laskin, J.J. \& Sandler, A.B. (2004). Epidermal growth factor receptor: a promising target in solid tumours. Cancer Treat Rev, 30:1-17.

Le Page, C.; Koumakpayi, I.H.; Alam-Fahmy, M.; Mes-Masson, A.M. \& Saad, F. (2006). Expression and localisation of Akt-1, Akt-2 and Akt-3 correlate with clinical outcome of prostate cancer patients. Br J Cancer, 94:1906-12.

Lee, M.Y.; Chou, C.Y.; Tang, M.J. \& Shen, M.R. (2008). Epithelial-mesenchymal transition in cervical cancer: correlation with tumor progression, epidermal growth factor receptor overexpression, and snail up-regulation. Clin Cancer Res, 14:4743-50.

Levkowitz, G.; Waterman, H.; Ettenberg, S.A.; Katz, M.; Tsygankov, A.Y.; Alroy, I.; Lavi, S.; Iwai, K.; Reiss, Y.; Ciechanover, A.; Lipkowitz, S. \& Yarden, Y. (1999). Ubiquitin ligase activity and tyrosine phosphorylation underlie suppression of growth factor signaling by c-Cbl/Sli-1. Mol Cell, 4:1029-40.

Levkowitz, G.; Waterman, H.; Zamir, E.; Kam, Z.; Oved, S.; Langdon, W.Y.; Beguinot, L.; Geiger, B. \& Yarden, Y. (1998). c-Cbl/Sli-1 regulates endocytic sorting and ubiquitination of the epidermal growth factor receptor. Genes Dev, 12:3663-74.

Li, J.; Yen, C.; Liaw, D.; Podsypanina, K.; Bose, S.; Wang, S.I.; Puc, J.; Miliaresis, C.; Rodgers, L.; McCombie, R.; Bigner, S.H.; Giovanella, B.C.; Ittmann, M.; Tycko, B.; Hibshoosh, H.; Wigler, M.H. \& Parsons, R. (1997). PTEN, a putative protein tyrosine phosphatase gene mutated in human brain, breast, and prostate cancer. Science, 275:1943-7.

Li, X.; Huang, Y.; Jiang, J. \& Frank, S.J. (2008). ERK-dependent threonine phosphorylation of EGF receptor modulates receptor downregulation and signaling. Cell Signal, 20:2145-55.

Lichtner, R.B. (2003). Estrogen/EGF receptor interactions in breast cancer: rationale for new therapeutic combination strategies. Biomedicine Pharmacotherapy, 57:447-51.

Liu, X.H.; Wiley, H.S. \& Meikle, A.W. (1993). Androgens regulate proliferation of human prostate cancer cells in culture by increasing transforming growth factor-alpha (TGF-alpha) and epidermal growth factor (EGF)/TGF-alpha receptor. J Clin Endocrinol Metab, 77:1472-8.

Lowenstein, E.J.; Daly, R.J.; Batzer, A.G.; Li, W.; Margolis, B.; Lammers, R.; Ullrich, A.; Skolnik, E.Y.; Bar-Sagi, D. \& Schlessinger, J. (1992). The SH2 and SH3 domaincontaining protein GRB2 links receptor tyrosine kinases to ras signaling. Cell, 70:431-42.

Lu, J.; Guo, H.; Treekitkarnmongkol, W.; Li, P.; Zhang, J.; Shi, B.; Ling, C.; Zhou, X.; Chen, T.; Chiao, P.J.; Feng, X.; Seewaldt, V.L.; Muller, W.J.; Sahin, A.; Hung, M.C. \& Yu, D. (2009). 14-3-3zeta Cooperates with ErbB2 to promote ductal carcinoma in situ 
progression to invasive breast cancer by inducing epithelial-mesenchymal transition. Cancer Cell, 16:195-207.

Lu, Q.; Hope, L.W.; Brasch, M.; Reinhard, C. \& Cohen, S.N. (2003). TSG101 interaction with HRS mediates endosomal trafficking and receptor down-regulation. Proc Natl Acad Sci U S A, 100:7626-31.

Lu, Z.; Ghosh, S.; Wang, Z. \& Hunter, T. (2003). Downregulation of caveolin-1 function by EGF leads to the loss of E-cadherin, increased transcriptional activity of betacatenin, and enhanced tumor cell invasion. Cancer Cell, 4:499-515.

Lund, K.A.; Lazar, C.S.; Chen, W.S.; Walsh, B.J.; B., W.J.; Herbst, J.J.; Walton, G.M.; Rosenfeld, M.G.; Gill, G.N. \& Wiley, H.S. (1990). Phosphorylation of the epidermal growth factor receptor at threonine 654 inhibits ligand-induced internalization and down-regulation. J Biol Chem, 265:20517-23.

Marais, R.; Light, Y.; Paterson, H.F.; Mason, C.S. \& Marshall, C.J. (1997). Differential regulation of Raf-1, A-Raf, and B-Raf by oncogenic ras and tyrosine kinases. J Biol Chem, 272:4378-83.

Marais, R. \& Marshall, C.J. (1996). Control of the ERK MAP kinase cascade by Ras and Raf. Cancer Surv, 27:101-25.

Marks, R.A.; Zhang, S.; Montironi, R.; McCarthy, R.P.; MacLennan, G.T.; Lopez-Beltran, A.; Jiang, Z.; Zhou, H.; Zheng, S.; Davidson, D.D.; Baldridge, L.A. \& Cheng, L. (2008). Epidermal growth factor receptor (EGFR) expression in prostatic adenocarcinoma after hormonal therapy: a fluorescence in situ hybridization and immunohistochemical analysis. Prostate, 68:919-23.

Maroulakou, I.G.; Oemler, W.; Naber, S.P.; Klebba, I.; Kuperwasser, C. \& Tsichlis, P.N. (2008). Distinct roles of the three Akt isoforms in lactogenic differentiation and involution. J Cell Physiol, 217:468-77.

Massagué, J. \& Pandiella, A. (1993). Membrane-anchored growth factors. Annu Rev Biochem, 62:515-41.

McKay, M.M. \& Morrison, D.K. (2007). Integrating signals from RTKs to ERK/MAPK. Oncogene, 26:3113-21.

Mirzoeva, O.K.; Das, D.; Heiser, L.M.; Bhattacharya, S.; Siwak, D.; Gendelman, R.; Bayani, N.; Wang, N.J.; Neve, R.M.; Guan, Y.; Hu, Z.; Knight, Z.; Feiler, H.S.; Gascard, P.; Parvin, B.; Spellman, P.T.; Shokat, K.M.; Wyrobek, A.J.; Bissell, M.J.; McCormick, F.; Kuo, W.L.; Mills, G.B.; Gray, J.W. \& Korn, W.M. (2009). Basal subtype and MAPK/ERK kinase (MEK)-phosphoinositide 3-kinase feedback signaling determine susceptibility of breast cancer cells to MEK inhibition. Cancer Res, 69:565-72.

Morandell, S.; Stasyk, T.; Skvortsov, S.; Ascher, S. \& Huber, L.A. (2008). Quantitative proteomics and phosphoproteomics reveal novel insights into complexity and dynamics of the EGFR signaling network. Proteomics, 8:4383-401.

Moreno-Bueno, G.; Portillo, F. \& Cano, A. (2008). Transcriptional regulation of cell polarity in EMT and cancer. Oncogene, 27:6958-69.

Morgan, T.M.; Koreckij, T.D. \& Corey, E. (2009). Targeted therapy for advanced prostate cancer: inhibition of the PI3K/Akt/mTOR pathway. Curr Cancer Drug Targets, 9:237-49. 
Neto, A.S.; Tobias-Machado, M.; Wroclawski, M.L.; Fonseca, F.L.; Pompeo, A.C. \& Del Giglio, A. (2010). Molecular oncogenesis of prostate adenocarcinoma: role of the human epidermal growth factor receptor 2 (HER-2/neu). Tumori, 96:645-9.

Nicholson, K.M. \& Anderson, N.G. (2002). The protein kinase B/Akt signalling pathway in human malignancy. Cell Signal, 14:381-95.

Nicholson, R.I.; Gee, J.M. \& Harper, M.E. (2001). EGFR and cancer prognosis. Eur J Cancer, 37 Suppl 4:S9-15.

Northwood, I.C.; Gonzalez, F.A.; Wartmann, M.; Raden, D.L. \& Davis, R.J. (1991). Isolation and characterization of two growth factor-stimulated protein kinases that phosphorylate the epidermal growth factor receptor at threonine 669. J Biol Chem, 266:15266-76.

Olapade-Olaopa, E.O.; Moscatello, D.K.; MacKay, E.H.; Horsburgh, T.; Sandhu, D.P.; Terry, T.R.; Wong, A.J. \& Habib, F.K. (2000). Evidence for the differential expression of a variant EGF receptor protein in human prostate cancer. Br J Cancer, 82:186-94.

Olayioye, M.A.; Neve, R.M.; Lane, H.A. \& Hynes, N.E. (2000). The ErbB signaling network: receptor heterodimerization in development and cancer. EMBO J, 19:3159-67.

Orth, J.D.; Krueger, E.W.; Weller, S.G. \& McNiven, M.A. (2006). A novel endocytic mechanism of epidermal growth factor receptor sequestration and internalization. Cancer Res, 66:3603-10.

Pearson, R.B. \& Kemp, B.E. (1991). Protein kinase phosphorylation site sequences and consensus specificity motifs: tabulations. Methods Enzymol, 200:62-81.

Peinado, H.; Olmeda, D. \& Cano, A. (2007). Snail, Zeb and bHLH factors in tumour progression: an alliance against the epithelial phenotype? Nat Rev Cancer, 7:415-28.

Pennock, S. \& Wang, Z. (2003). Stimulation of cell proliferation by endosomal epidermal growth factor receptor as revealed through two distinct phases of signaling. Mol Cell Biol, 23:5803-15.

Polo, S.; Pece, S. \& Di Fiore, P.P. (2004). Endocytosis and cancer. Curr Opin Cell Biol, 16:156-61.

Polo, S.; Sigismund, S.; Faretta, M.; Guidi, M.; Capua, M.R.; Bossi, G.; Chen, H.; De Camilli, P. \& Di Fiore, P.P. (2002). A single motif responsible for ubiquitin recognition and monoubiquitination in endocytic proteins. Nature, 416:451-5.

Prenzel, N.; Zwick, E.; Leserer, M. \& Ullrich, A. (2000). Tyrosine kinase signaling in breast cancer: epidermal growth factor receptor: convergence point for signal integration and diversification. Breast Cancer Res, 2:184-90.

Qiao, M.; Sheng, S. \& Pardee, A.B. (2008). Metastasis and AKT activation. Cell Cycle, 7:2991-6.

Quilliam, L.A.; Khosravi-Far, R.; Huff, S.Y. \& Der, C.J. (1995). Guanine nucleotide exchange factors: activators of the Ras superfamily of proteins. Bioessays, 17:395-404.

Ratan, H.L.; Gescher, A.; Steward, W.P. \& Mellon, J.K. (2003). ErbB receptors: possible therapeutic targets in prostate cancer? BJU Intl, 92:890-5.

Reutens, A.T. \& Begley, C.G. (2002). Endophilin-1: a multifunctional protein. Int J Biochem Cell Biol, 34:1173-7.

Rinehart, J.; Adjei, A.A.; Lorusso, P.M.; Waterhouse, D.; Hecht, J.R.; Natale, R.B.; Hamid, O.; Varterasian, M.; Asbury, P.; Kaldjian, E.P.; Gulyas, S.; Mitchell, D.Y.; Herrera, R.; Sebolt-Leopold, J.S. \& Meyer, M.B. (2004). Multicenter phase II study of the oral MEK inhibitor, CI-1040, in patients with advanced non-small-cell lung, breast, colon, and pancreatic cancer. J Clin Oncol, 22:4456-62. 
Roepstorff, K.; Grøvdal, L.; Grandal, M.; Lerdrup, M. \& van Deurs, B. (2008). Endocytic downregulation of ErbB receptors: mechanisms and relevance in cancer. Histochem Cell Biol, 129:563-78.

Salcini, A.E.; Chen, H.; Iannolo, G.; De Camilli, P. \& Di Fiore, P.P. (1999). Epidermal growth factor pathway substrate 15, Eps15. Int J Biochem Cell Biol, 31:805-9.

Salomon, D.S.; Brandt, R.; Ciardiello, F. \& Normanno, N. (1995). Epidermal growth factorrelated peptides and their receptors in human malignancies. Crit Rev Oncol Hematol, 19:183-232.

Sansal, I. \& Sellers, W.R. (2004). The biology and clinical relevance of the PTEN tumor suppressor pathway. J Clin Oncol, 22:2954-63.

Scher, H.I.; Sarkis, A.; Reuter, V.; Cohen, D.; Netto, G.; Petrylak, D.; Lianes, P.; Fuks, Z.; Mendelsohn, J. \& Cordon-Cardo, C. (1995). Changing pattern of expression of the epidermal growth factor receptor and transforming growth factor alpha in the progression of prostatic neoplasms. Clin Cancer Res, 1:545-50.

Schlomm, T.; Kirstein, P.; Iwers, L.; Daniel, B.; Steuber, T.; Walz, J.; Chun, F.H.; Haese, A.; Kollermann, J.; Graefen, M.; Huland, H.; Sauter, G.; Simon, R. \& Erbersdobler, A. (2007). Clinical significance of epidermal growth factor receptor protein overexpression and gene copy number gains in prostate cancer. Clin Cancer Res, 13:6579-84.

Sebastian, S.; Settleman, J.; Reshkin, S.; Azzariti, A.; Bellizzi, A. \& Paradiso, A. (2006). The complexity of targeting EGFR signalling in cancer: from expression to turnover. Biochim Biophys Acta, 1766:120-39.

Sengupta, P.; Bosis, E.; Nachliel, E.; Gutman, M.; Smith, S.O.; Mihályné, G.; Zaitseva, I. \& McLaughlin, S. (2009). EGFR juxtamembrane domain, membranes, and calmodulin: kinetics of their interaction. Biophys J, 96:4887-95.

Seth, D.; Shaw, K.; Jazayeri, J. \& Leedman, P.J. (1999). Complex post-transcriptional regulation of EGF-receptor expression by EGF and TGF-alpha in human prostate cancer cells. Br J Cancer, 80:657-69.

Sharma, S.V.; Bell, D.W.; Settleman, J. \& Haber, D.A. (2007). Epidermal growth factor receptor mutations in lung cancer. Nat Rev Cancer, 7:169-81.

Sherwood, E.R. \& Lee, C. (1995). Epidermal growth factor-related peptides and the epidermal growth factor receptor in normal and malignant prostate. World J Urol, 13:290-6.

Shoelson, S.E. (1997). SH2 and PTB domain interactions in tyrosine kinase signal transduction. Curr Opin Chem Biol, 1:227-34.

Sigismund, S.; Woelk, T.; Puri, C.; Maspero, E.; Tacchetti, C.; Transidico, P.; Di Fiore, P.P. \& Polo, S. (2005). Clathrin-independent endocytosis of ubiquitinated cargos. Proc Natl Acad Sci U S A, 102:2760-5.

Singh, A.B. \& Harris, R.C. (2005). Autocrine, paracrine and juxtacrine signaling by EGFR ligands. Cell Signal, 17:1183-93.

Sorkin, A. \& von Zastrow, M. (2009). Endocytosis and signalling: intertwining molecular networks. Nat Rev Mol Cell Biol, 10:609-22.

Soubeyran, P.; Kowanetz, K.; Szymkiewicz, I.; Langdon, W.Y. \& Dikic, I. (2002). Cbl-CIN85endophilin complex mediates ligand-induced downregulation of EGF receptors. Nature, 416:183-7. 
Staal, S.P. (1987). Molecular cloning of the akt oncogene and its human homologues AKT1 and AKT2: amplification of AKT1 in a primary human gastric adenocarcinoma. Proc Natl Acad Sci U S A, 84:5034-7.

Staal, S.P. \& Hartley, J.W. (1998). Thymic lymphoma induction by the AKT8 murine retrovirus. J Exp Med, 167:1259-64.

Stang, E.; Blystad, F.D.; Kazazic, M.; Bertelsen, V.; Brodahl, T.; Raiborg, C.; Stenmark, H. \& Madshus, I.H. (2004). Cbl-dependent ubiquitination is required for progression of EGF receptors into clathrin-coated pits. Mol Biol Cell, 15:3591-604.

Sudol, M. (1998). From Src Homology domains to other signaling modules: proposal of the 'protein recognition code'. Oncogene, 17:1469-74.

Takishima, K.; Friedman, B.; Fujiki, H. \& Rosner, M.R. (1988). Thapsigargin, a novel promoter, phosphorylates the epidermal growth factor receptor at threonine 669. Biochem Biophys Res Commun, 157:740-6.

Takishima, K.; Griswold-Prenner, I.; Ingebritsen, T. \& Rosner, M.R. (1991). Epidermal growth factor (EGF) receptor T669 peptide kinase from 3T3-L1 cells is an EGFstimulated "MAP" kinase. Proc Natl Acad Sci U S A, 88:2520-4.

Taub, N.; Teis, D.; Ebner, H.L.; Hess, M.W. \& Huber, L.A. (2007). Late endosomal traffic of the epidermal growth factor receptor ensures spatial and temporal fidelity of mitogen-activated protein kinase signaling. Mol Biol Cell, 18:4698-710.

Tebar, F.; Sorkina, T.; Sorkin, A.; Ericsson, M. \& Kirchhausen, T. (1996). Eps15 is a component of clathrin-coated pits and vesicles and is located at the rim of coated pits. J Biol Chem, 271:28727-30.

Teis, D.; Taub, N.; Kurzbauer, R.; Hilber, D.; de Araujo, M.E.; Erlacher, M.; Offterdinger, M.; Villunger, A.; Geley, S.; Bohn, G.; Klein, C.; Hess, M.W. \& Huber, L.A. (2006). p14MP1-MEK1 signaling regulates endosomal traffic and cellular proliferation during tissue homeostasis. J Cell Biol, 175:861-8.

Teis, D.; Wunderlich, W. \& Huber, L.A. (2002). Localization of the MP1-MAPK scaffold complex to endosomes is mediated by p14 and required for signal transduction. Dev Cell, 3:803-14.

Theroux, S.J.; Stanley, K.; Campbell, D.A. \& Davis, R.J. (1992a). Mutational removal of the major site of serine phosphorylation of the epidermal growth factor receptor causes potentiation of signal transduction: role of receptor down-regulation. Mol Endocrinol, 6:1849-57.

Theroux, S.J.; Taglienti-Sian, C.; Nair, N.; Countaway, J.L.; Robinson, H.L. \& Davis, R.J. (1992b). Increased oncogenic potential of ErbB is associated with the loss of a COOH-terminal domain serine phosphorylation site. J Biol Chem, 267:7967-70.

Thiery, J.P. (2002). Epithelial-mesenchymal transitions in tumour progression. Nat Rev Cancer, 2:442-54.

Thiery, J.P. (2003). Epithelial-mesenchymal transitions in development and pathologies. Curr Opin Cell Biol, 15:740-6.

Thiery, J.P. \& Sleeman, J.P. (2006). Complex networks orchestrate epithelial-mesenchymal transitions. Nat Rev Mol Cell Biol, 7:131-42.

Tzahar, E.; Waterman, H.; Chen, X.; Levkowitz, G.; Karunagaran, D.; Lavi, S.; Ratzkin, B.J. \& Yarden, Y. (1996). A hierarchical network of interreceptor interactions determines 
signal transduction by Neu differentiation factor/neuregulin and epidermal growth factor. Mol Cell Biol, 16:5276-87.

Umbas, R.; Isaacs, W.B.; Bringuier, P.P.; Schaafsma, H.E.; Karthaus, H.F.; Oosterhof, G.O.; Debruyne, F.M. \& Schalken, J.A. (1994). Decreased E-cadherin expression is associated with poor prognosis in patients with prostate cancer. Cancer Res, 54:3929-33.

Umbas, R.; Schalken, J.A.; Aalders, T.W.; Carter, B.S.; Karthaus, H.F.; Schaafsma, H.E.; Debruyne, F.M. \& Isaacs, W.B. (1992). Expression of the cellular adhesion molecule E-cadherin is reduced or absent in high-grade prostate cancer. Cancer Res, 52:5104-9.

van Bokhoven, A.; Varella-Garcia, M.; Korch, C.; Johannes, W.U.; Smith, E.E.; Miller, H.L.; Nordeen, S.K.; Miller, G.J. \& Lucia, M.S. (2003). Molecular characterization of human prostate carcinoma cell lines. Prostate, 57:205-25.

Vanden Broeck, D. \& De Wolf, M.J. (2006). Selective blocking of clathrin-mediated endocytosis by RNA interference: epsin as target protein. Biotechniques, 41:475-84.

Wang, Y.; Pennock, S.; Chen, X. \& Wang, Z. (2002a). Endosomal signaling of epidermal growth factor receptor stimulates signal transduction pathways leading to cell survival. Mol Cell Biol, 22:7279-90.

Wang, Y.; Pennock, S.; Chen, X. \& Wang, Z. (2002b). Internalization of inactive EGF receptor into endosomes and the subsequent activation of endosome-associated EGF receptors. Epidermal growth factor. Sci STKE, 2002:pl17.

Ware, J.L. (1999). Growth factor network disruption in prostate cancer progression. Cancer Metastasis Rev, 17:443-7.

Waterman, H.; Katz, M.; Rubin, C.; Shtiegman, K.; Lavi, S.; Elson, A.; Jovin, T. \& Yarden, Y. (2002). A mutant EGF-receptor defective in ubiquitylation and endocytosis unveils a role for Grb2 in negative signaling. EMBO J, 21:303-13.

Waterman, H.; Levkowitz, G.; Alroy, I. \& Yarden, Y. (1999). The RING finger of c-Cbl mediates desensitization of the epidermal growth factor receptor. J Biol Chem, 274:22151-4.

Wells, A. (1999). EGF receptor. Intl J Biochem Cell Biol, 31:637-43.

Wells, A.; Welsh, J.B.; Lazar, C.S.; Wiley, H.S.; Gill, G.N. \& Rosenfeld, M.G. (1990). Ligandinduced transformation by a noninternalizing epidermal growth factor receptor. Science, 247:962-4.

Wiley, H.S. (2003). Trafficking of the ErbB receptors and its influence on signaling. Exp Cell Res, 284:78-88.

Wiley, H.S.; Shvartsman, S.Y. \& Lauffenburger, D.A. (2003). Computational modeling of the EGF-receptor system: a paradigm for systems biology. Trends Cell Biol, 13:43-50.

Williams, R.L. \& Urbé, S. (2007). The emerging shape of the ESCRT machinery. Nat Rev Mol Cell Biol, 8:355-68.

Yamazaki, T.; Zaal, K.; Hailey, D.; Presley, J.; Lippincott-Schwartz, J. \& Samelson, L.E. (2002). Role of Grb2 in EGF-stimulated EGFR internalization. J Cell Sci, 115:1791802.

Yarden, Y. (2001). The EGFR family and its ligands in human cancer: signaling mechanisms and therapeutic opportunities. Eur J Cancer, 37:S3-S8. 
Yarden, Y. \& Sliwkowski, M.X. (2001). Untangling the ErbB signalling network. Nat Rev Mol Cell Biol, 2:127-37.

Yoon, S. \& Seger, R. (2006). The extracellular signal-regulated kinase: multiple substrates regulate diverse cellular functions. Growth Factors, 24:21-44.

Zhang, D.; Sliwkowski, M.X.; Mark, M.; Frantz, G.; Akita, R.; Sun, Y.; Hillan, K.; Crowley, C.; Brush, J. \& Godowski, P.J. (1997). Neuregulin-3 (NRG3): a novel neural tissueenriched protein that binds and activates ErbB4. Proc Natl Acad Sci U S A, 94:9562-7.

Zhou, B.P.; Deng, J.; Xia, W.; Xu, J.; Li, Y.M.; Gunduz, M. \& Hung, M.C. (2004). Dual regulation of Snail by GSK-3beta-mediated phosphorylation in control of epithelialmesenchymal transition. Nat Cell Biol, 6:931-40. 


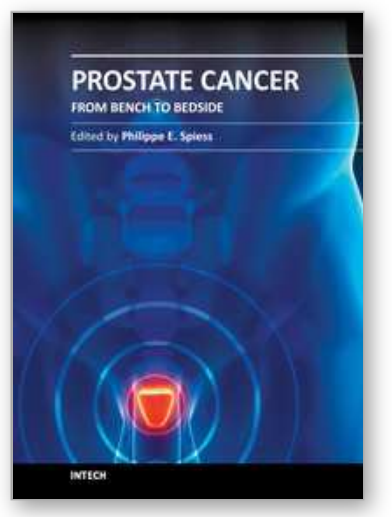

\section{Prostate Cancer - From Bench to Bedside}

Edited by Dr. Philippe E. Spiess

ISBN 978-953-307-331-6

Hard cover, 528 pages

Publisher InTech

Published online 25, November, 2011

Published in print edition November, 2011

The present textbook highlights many of the exciting discoveries made in the diagnosis and treatment of prostate cancer over the past decade. International thought leaders have contributed to this effort providing a comprehensive and state-of-the art review of the signaling pathways and genetic alterations essential in prostate cancer. This work provides an essential resource for healthcare professionals and scientists dedicated to this field. This textbook is dedicated to the efforts and advances made by our scientific community, realizing we have much to learn in striving to some day in the not too distant future cure this disease particularly among those with an aggressive tumor biology.

\section{How to reference}

In order to correctly reference this scholarly work, feel free to copy and paste the following:

Yao Huang and Yongchang Chang (2011). Epidermal Growth Factor Receptor (EGFR) Phosphorylation, Signaling and Trafficking in Prostate Cancer, Prostate Cancer - From Bench to Bedside, Dr. Philippe E. Spiess (Ed.), ISBN: 978-953-307-331-6, InTech, Available from: http://www.intechopen.com/books/prostate-cancerfrom-bench-to-bedside/epidermal-growth-factor-receptor-egfr-phosphorylation-signaling-and-trafficking-inprostate-cancer

\section{INTECH}

open science | open minds

\section{InTech Europe}

University Campus STeP Ri

Slavka Krautzeka 83/A

51000 Rijeka, Croatia

Phone: +385 (51) 770447

Fax: +385 (51) 686166

www.intechopen.com

\section{InTech China}

Unit 405, Office Block, Hotel Equatorial Shanghai

No.65, Yan An Road (West), Shanghai, 200040, China

中国上海市延安西路65号上海国际贵都大饭店办公楼405单元

Phone: +86-21-62489820

Fax: +86-21-62489821 
(C) 2011 The Author(s). Licensee IntechOpen. This is an open access article distributed under the terms of the Creative Commons Attribution 3.0 License, which permits unrestricted use, distribution, and reproduction in any medium, provided the original work is properly cited. 